\title{
AIAA 97-0274
}

Isolated Roughness Induced Boundary-Layer Transition:

Shuttle Orbiter Ground Tests

and

Flight Experience

S. A. Bouslog

Rohr, Inc., Chula Vista, CA

J. J. Bertin

USAF Academy, Colorado Springs, CO

S. A. Berry

NASA LaRC, Hampton, VA

J. M. Caram

NASA JSC, Houston, TX

\section{5th Aerospace Sciences Meeting \& Exhibit January 6-10, 1997 / Reno, NV}




\title{
ISOLATED ROUGHNESS INDUCED BOUNDARY -LAYER TRANSITION: SHUTTLE ORBITER GROUND TESTS AND FLIGHT EXPERIENCE
}

\author{
Stanley A. Bouslog \\ Rohr, Inc., Chula Vista, CA \\ John J. Bertin \\ USAF Academy, Colorado Springs, $C O$ \\ Scott A. Berry \\ NASA LaRC, Hampton, VA \\ Jose M. Caram \\ NASA JSC, Houston, TX
}

\begin{abstract}
Recent Orbiter wind tunnel data and flight data have been used to evaluate boundary-layer transition induced by discrete-roughness elements on the Orbiter windward surface. Orbiter flow field calculations have been used to compute transition parameters and disturbance parameters for correlating the results and comparing the trends. Existing transition correlations have been modified and applied to the Orbiter. These correlations provide a means to predict transition on the Orbiter given a known isolated roughness element. Furthermore, these data and data reduction methods provide information and guidance for the prediction of transition due to discrete-roughness elements on future winged reentry vehicles.
\end{abstract}

\section{Nomenclature}

\begin{tabular}{|c|c|}
\hline B & Velocity gradient parameter \\
\hline k & Roughness height \\
\hline Keq & Equivalent roughness height \\
\hline L & $\begin{array}{l}\text { Orbiter reference length - } 107.75 \mathrm{ft} \text { full- } \\
\text { scale }\end{array}$ \\
\hline $\mathrm{M}_{\mathbf{e}}$ & Boundary-layer edge Mach number \\
\hline $\operatorname{Re} \delta^{*}$ & Displacement thickness Reynolds number \\
\hline $\operatorname{Re}_{\mathbf{k}}$ & $\begin{array}{l}\text { Reynolds number based upon conditions at } \\
\text { roughness height }\end{array}$ \\
\hline $\mathbf{R}_{\mathbf{n}}$ & Nose radius \\
\hline $\operatorname{Re} \theta$ & Momentum thickness Reynolds number \\
\hline & Edge temperature \\
\hline$T_{w}$ & Wall temperature \\
\hline
\end{tabular}

Copyright 11997 by the American Institute of Aeromautics and Astronautics, Inc. All rights reserved.

$\begin{array}{ll}X / L & \begin{array}{l}\text { Axial distance from Orbiter nose tip } \\ \text { divided by reference length }\end{array} \\ (X / L) t & \text { Axial location for transition front } \\ \delta & \text { Boundary-layer thickness } \\ \delta^{*} & \text { Displacement thickness } \\ \theta & \text { Momentum thickness }\end{array}$

\section{Introduction}

During the entry phase of several Space Shuttle Orbiter flights, temperature instrumentation has indicated higher than normal heating to the Orbiter windward surface. Furthermore, control surface and reaction control jet activity have indicated unaccounted for moments acting on the vehicle. Although both of these events are well within the design limits of the Orbiter, their occurrence was cause for investigation. In both cases, these anomalies have been attributed to early and/or asymmetric boundary-layer transition. During STS-28, surface thermocouples indicated that transition began at 900 seconds into the entry at Mach number of 18 (see ref. 1). Nominally, transition occurs at approximately 1200 seconds at a Mach number of 8 . This anomalous event has been attributed to gap fillers protruding into the boundary layer (ref. 1). During STS-50, Orbiter elevon deflections and yaw reaction control jet firings indicated that the vehicle experienced a yawing moment during the same time as transition occurred. Surface thermocouple data confirmed that transition occurred on the right side of the vehicle 80 seconds prior to occurring on the left side. These anomalies in the Orbiter entry have raised concerns about the understanding of boundary-layer transition on the Orbiter. 
It is known that boundary-layer transition occurs due to the amplification of disturbances introduced into the laminar boundary-layer. Significant research has been conducted (see Reshotko, ref. 2) to model the growth of disturbances in the laminar boundary layer and this research has lead to a better understanding of the transition process. However, empirical data are still needed to predict the onset of transition and most of our understanding of transition is associated with those disturbances which can be modeled by linear stability theory. For some disturbances, transition occurs by-passing the known linear processes (see Stetson, ref. 3). Transition on the Orbiter is dominated by at least two known by-pass mechanisms - the blunt-body paradox (ref. 3 ) and surface roughness. The existence of these bypass mechanisms makes it extremely difficult to develop analytical models to investigate boundary-layer transition on the Orbiter. Therefore, a plan was developed in which the available Orbiter transition flight data and previously obtained Orbiter transition wind tunnel data would be reviewed and compared. Furthermore, new Orbiter transition experiments would be conducted to specifically investigate the effects of isolated roughness elements on the Orbiter windward surface. Two experimental programs were conducted. The first experiment was conducted in June 1995 at the Amold Engineering Development Center (AEDC) Tunnel B with a $1.75 \%$ scale Orbiter model (refs. 4 and 5). The second experiment was conducted at the NASA Langley Mach 6 wind tunnel using a $0.75 \%$ Orbiter model (ref. 6 ). It is the objective of this paper to compare the results of Orbiter wind tunnel transition tests, both previous and present, and Orbiter flight transition data. This effort provides a unique opportunity to evaluate the results of transition data obtained in two different wind tunnel facilities and how these results compare to flight results. Furthermore, it is hoped that this comparison can be used to better understand boundary-layer transition events on the Space Shuttle Orbiter during flight and to evaluate several roughness transition correlations that could be used to predict transition.

\section{Orbiter Transition Fight Data}

A significant amount of Orbiter surface thermocouple data are available from which the time and free stream conditions for boundary-layer transition at the thermocouple location have been determined. These data indicate that nominally the Orbiter experiences transition at Mach number $=8$ and at a free stream Reynolds number of 8 million based upon length. However, transition has occurred over a wide range of free stream conditions - Mach numbers between 6 and 18 and Reynolds numbers between 2.5 and 13 million. See Refs. 1 and 7. The problem with these data is that the roughness condition of the Orbiter during flight is not well characterized. Before first flight of the Orbiter vehicles, the equivalent roughness, $K_{\text {eq }}$, has been determined to ensure that the windward surface roughness is within the specified allowable roughness. Goodrich et al (ref. 7) presents the $\mathrm{K}_{\mathrm{eq}}$ distribution along the windward centerline of the OV-102 Orbiter prior to STS-1. For this vehicle, $\mathrm{K}_{\mathrm{eq}}$ varies from 0.035 to 0.090 inches along the centerline and Goodrich et al has chosen an average value of 0.060 in. to characterize the distributed roughness on OV-102. The newest of the Orbiters, OV-105, is a smoother vehicle with an average distributed roughness of 0.050 inches based upon unpublished measurements of the steps and gaps along the windward surface centerline prior to its first flight - STS-47. These two values provide a reasonable indicator of the nominal distributed roughness of the Orbiter windward surface.

Nevertheless, preflight measurements do not necessarily provide a good representation of the Orbiter roughness during reentry into the atmosphere. During launch and onorbit operations minor damage is often experienced by the thermal protection system (TPS) tiles (ref. 1). The damage usually consists of cavities into the tiles. Furthermore, some gap fillers inserted into gaps between tiles loosen and protrude into the boundary layer. After reviewing Orbiter flight data, two cases were found in which the connection between boundary-layer transition and a 'known' isolated roughness element protruding into the flow was identified flights STS-28 and STS-73. For both of these cases, transition occurred at approximately Mach number $=18$ and at a free stream Reynolds number of 2.5 million. After landing, the vehicle is inspected and after STS-28, two charred gap fillers were found protruding 0.25 inches from the surface at locations of $\mathrm{X} / \mathrm{L}=0.26$ and 20 in. off centerline and $X / L=0.4$ and 95 in. off centerline. After STS-73, a gap filler was found protruding from the surface by 0.6 inches near the windward centerline at $\mathrm{X} / \mathrm{L}=0.19$. After reviewing the location of these gap fillers and the flight thermocouple data, the gap filler at $\mathrm{X} / \mathrm{L}=0.4$ for STS- 28 and the gap filler at $X / L=0.19$ for STS-73 were identified as the possible causes of early transition. Figure 1 provides a sketch of the Orbiter planform with these locations identified. Figure 2 includes a sketch of the isolated roughness element produced by the protruding gap filler. To evaluate the hypothesis that a single gap filler, that is a fraction of the boundary-layer thickness, could cause early boundary-layer transition on the Orbiter, wind tunnel tests were conducted in which isolated roughness elements were located in similar locations as shown in Figure 1.

\section{Wind Tunnel Transition Experiments}

\section{Smooth-Body and Distributed Roughness Transition Tests}

In the development of the Orbiter flight vehicle numerous wind tunnel tests were conducted to obtain a better 
understanding of boundary-layer transition on the Orbiter. The most significant tests were conducted with a smooth windward surface or with distributed roughness elements. The smooth body tests included Orbiter heat transfer tests $\mathrm{OH} 49 \mathrm{~B}, \mathrm{OH} 39 \mathrm{~A} / \mathrm{B}, \mathrm{OH} 84 \mathrm{~B}, \mathrm{OH} 103 \mathrm{~A}$, and OH54A - which were all conducted with various models of the Orbiter at angles-of-attack ranging from $30^{\circ}$ to $40^{\circ}$ (ref. 8). Furthermore, a series of wind tunnel tests $\mathrm{OH} 4 \mathrm{~A}, \mathrm{MH} 2 \mathrm{~A}$, and $\mathrm{MH} 2 \mathrm{~B}$ (refs. 9, 10, and 11) were conducted with a $1.75 \%$ scale stainless-steel model of the Orbiter in AEDC Von Karman Tunnel B with a nominal Mach number of 8 . For OH4A the surface was smooth. However, for MH2A and $M H 2 B$ the windward surface was covered with simulated raised tiles from $x=0.02$ to $0.80 \mathrm{~L}$. These misaligned tiles represented $25 \%$ percent of the tiles in this region. The $\mathrm{MH} 2 \mathrm{~A}$ test used 0.001 in. simulated raised tiles' whereas MH2B used 0.002 in. simulated tiles.

\section{AEDC Discrete Roughness-Induced Transition Test MH- 11}

Using the same model as tested in $\mathrm{OH} 4 \mathrm{~A}, \mathrm{MH} 2 \mathrm{~A}$, and $\mathrm{MH} 2 \mathrm{~B}$, a discrete-roughness transition test $(\mathrm{MH}-11)$ was conducted in AEDC Tunnel B (ref. 4). A pattern of simulated tiles had been etched into the windward surface of this model for test MH2B and they were polished to represent a distributed roughness of no more than 0.001 inch in height. Discrete roughness elements could be located at 11 different locations on the windward surface, as shown in Fig. 1. The locations have been labeled by a letter from A to $\mathrm{K}$. The stainless-steel discrete roughness elements were 0.0525 inches wide, 0.01 inches thick, and varied between 0.004 and 0.015 inches in height (see Fig 2). These rectangular-shaped elements were mounted to the model such that they were aligned $45^{\circ}$ relative to the model centerline. In most cases, only one roughness element was positioned on the model for a run. However, for several runs, two roughness elements were used during the same run. The windward surface of the model was instrumented with 55 co-axial heat flux gages (ref. 4). For each configuration, data were obtained at several free stream Reynolds numbers in order to bound the Reynolds number to bring the transition front to the element. Most of the data were obtained at an angle-of-attack of $40^{\circ}$ and a wall temperature of approximately $540^{\circ} R$. However, a significant amount of data were obtained at $35^{\circ}$ angle-of-attack and for wall temperatures of approximately $200^{\circ} \mathrm{R}$. An overview of the $A E D C$ test and the results have been presented in Ref. 5 . The detailed test report is available in Ref. 4.

\section{NASA LaRC Discrete Roughness-Induced Transition Test}

A $0.75 \%$ scale ceramic model of the Orbiter was tested in the NASA LaRC 20-inch Mach 6 Tunnel. The windward surface of this model was coated with thermographic phosphors and a thermographic system was used to determine the heating rate distribution on the model. Roughness elements that consisted of 0.050 in. squares of kapton tape were positioned at locations B, D, and G as shown in Figure 1, which are the same locations investigated in the AEDC test. Additionally, the locations DE and EC were tested. Roughness heights varied between 0.0025 and 0.010 inches and the elements were attached such that a pair of the comers were aligned with the centerline (see Figure 2). Therefore, these elements simulated a Shuttle tile that protruded from the otherwise smooth surface. All of these tests were conducted at $40^{\circ}$ angle-of-attack and for wall temperatures of approximately 540 to $620^{\circ} \mathrm{R}$. For each roughness element configuration, the free stream Reynolds number was varied in attempt to determine the Reynolds number that brought the transition front to or near the roughness element Ref. 6 presents a more detailed description of this test and the results.

\section{Scaling from Wind Tunnel to Wind Tunnel and to Flight}

In order to compare the results of these wind tunnel tests and the flight data it is necessary to compare the flow field characteristics. Typically, the free stream Reynolds number is used as a scaling parameter from wind tunnel to flight. Figure 3 presents the Reynolds number history, based upon length, for the Orbiter during the reentry portion of the STS2 mission. Typically, transition occurs at a free stream Reynolds numbers of $\mathbf{8}$ million with early transition occurring for Reynolds numbers as low as $\mathbf{2 . 5}$ million (ref. 1). Overlaid on the plot in Fig. 3 is the Reynolds number range tested in the two wind tunnel tests using the scaled model lengths. As can be observed, the wind tunnel values are within the range of interest for the occurrence of transition during flight. Free stream Mach number is another scaling parameter that is desired to be matched in wind tunnel tests. Unfortunately, only the lower end of the Mach number range of interest could be matched in the available wind tunnels. Nevertheless, for boundary-layer transition studies it is necessary to compare the characteristics of the boundary layer on the wind tunnel models to those in flight. To accomplish this task, computations of the boundary-layer flow parameters are needed.

A two-layer approach has been used to compute the boundary-layer flow on the Orbiter windward surface at wind tunnel and flight conditions. The two-layer approach used is a three step process. First, an inviscid flow field about the Orbiter configuration is computed. Second, using the inviscid flow field as input, a streamline tracing code is used to define inviscid streamlines with pressure distributions, streamline spreading metrics, and the boundary-layer edge entropy decrement along the streamline to the point of interest. Finally, a boundary-layer code is used to compute the surface heating rates and the boundary- 
layer parameters. The IVEC3D inviscid flow field solver (ret. 12) has been used to compute the perfect gas inviscid flow field for the Orbiter at $35^{\circ}$ and $40^{\circ}$ angle-of-attack and a AEDC wind tunnel condition of $\mathrm{Re} / \mathrm{ft}=1$ million. The IVEC3D code has also been used to compute the inviscid flow field about the Orbiter at seven flight conditions ranging from Mach 18.1 to Mach 6 for the STS-2 trajectory. (ref. 13) In this case, chemical equilibrium gas properties were used in the computations. The streamline code developed by Wang (ref. 14) has been used to generate the pressure, streamline-spreading metric, and the edge entropy distributions along inviscid streamlines. These distributions and the total enthalpy and stagnation pressure are input into the Boundary Layer Integral Matrix Procedure (BLIMP) code (ref. 15) to compute the surface heating rates and the boundary-layer parameters using a fixed wall temperature of $540^{\circ} \mathrm{R}$ or $200^{\circ} \mathrm{R}$ for the wind tunnel cases or a radiation equilibrium wall temperature for the flight cases. A perfect gas model was used by BLIMP for the wind tunnel computations and a chemical non-equilibrium gas model with finite surface reaction rates (ref. 16) was used for the two flight cases.

Using this method, the boundary-layer flow field parameters have been computed for correlating the results of the wind tunnel tests and for comparison to flight conditions. Figure 4 presents a comparison of the edge Mach number on the Orbiter windward centerline for two flight conditions - Mach 18 and Mach 13 - with the edge Mach number on the Orbiter models in the AEDC and the NASA LaRC wind tunnels. Note that the flight edge Mach numbers are supersonic and not hypersonic. Also, note that the wind tunnel values are almost half that of flight. Figure 5 presents a comparison of the boundary-layer thickness on the Orbiter centerline. The wind tunnel values have been divided by the model scale in order to make a more direct comparison with the full-scale vehicle. The relative thickness of the boundary layer is useful in scaling the wind tunnel roughness elements to the flight conditions.

In order to compare the trends of transition results from one case to another, parameters are chosen to represent the flow conditions at which transition occurs - the transition parameter. Typically, investigators choose the momentum thickness Reynolds number, $\operatorname{Re}_{\theta}$, which is often divided by the local Mach number. Figure 6 presents $\operatorname{Re}_{\theta}$ along the AEDC Orbiter model centerline for two wall temperatures at a unit Reynolds number of 1 million. Wall temperature has only a small effect on this parameter.

For roughness dominated transition, parameters which are based on the roughness height are used to represent the disturbance to the boundary layer. These parameters include the roughness Reynolds number, $\mathrm{Re}_{\mathrm{k}}$; the roughness height non-dimensionalized by the momentum thickness, $\mathrm{k} / \theta$; and the roughness height non-dimensionalized by the displacement thickness, $k / \delta^{*}$. The variation of $R e_{k}$ on the AEDC model centerline is presented in Figure 7 for two different roughness heights. This Reynolds number is based on the flow conditions at the top of the roughness. One of the problems of using $\mathrm{Re}_{\mathrm{k}}$ as a correlation parameter for roughness elements at different locations on the Orbiter is that values tend to be nearly constant over a large portion of the vehicle and often multi-valued. Wall temperature has a significant effect on this parameter as shown in Figure 7. Figure 8 presents the variation of the boundary-layer parameters, $\theta, \delta^{*}$, and $\delta$ on the AEDC model centerline for wall temperatures of $540{ }^{\circ} R$ and $200{ }^{\circ} R$. The wall temperature has little effect on the boundary-layer thickness, $\delta$, and the momentum thickness, $\theta$. However, for the cold wall temperature, the displacement thickness, $\delta^{*}$, is decreased significantly.

For the AEDC test (Table I), the NASA-LARC test (Table II), and the flight cases (Table III), the free stream unit Reynolds number, labeled $\mathrm{Re} / \mathrm{ft}$, for which the transition front has been brought up to or near the isolated roughness element has been determined. For these conditions, the boundary-layer parameters were computed and the results have been assembled into Tables I - III. The parameter B is the local streamwise velocity gradient and has been included in the tables to provide an indication of the pressure gradient at the roughness location.

Before these boundary-layer parameters are used for correlation of the transition results, it is of interest to know the three-dimensional characteristics of the boundary layer near the isolated roughness locations. Therefore, the inviscid and viscous streamlines on the Orbiter forebody, Figures 9 and 10 , respectively, are presented. The inviscid streamlines were determined from the surface velocity components computed by the IVEC3D code and they represent the streamlines at the boundary-layer edge. The viscous streamlines were determined from the shear stress components computed from a perfect gas Navier-Stokes solution provide by NASA LaRC using the LAURA code (Ref. 17). The attachment lines - the line separating the flow that continues down the vehicle from the flow that wraps around the vehicle - are clearly visible in these figures. The inward shift of the viscous attachment line indicates that the boundary-layer has significant cross-flow in those regions. The AEDC roughness element locations have been indicated in Figures 9 and 10 to provide the reader a relative indication of the cross-flow present at each location. 


\section{Discussion of Results}

\section{Smooth Bodv and Distabuted Roughness}

Figure 11 presents the $\operatorname{Re} \theta / M_{e}$ values to bring the transition front to locations on the Orbiter windward centerline as determined from smooth-body wind tunnel tests. The curvefit of these data represent a smooth-body correlation that has been referenced by Goodrich et al (ref. 7 ) and was used as a reference for developing the distributed roughness correlation developed by Bertin et al (ref. 18). This curve-fit is compared to flight results (STS-2 and STS-54) and to specific wind tunnel results in Figure 12a. The AEDC OH4A data (ref. 9) are for a $1.75 \%$ Orbiter model with a smooth surface tested in the AEDC Tunnel B at Mach 8. The AEDC - MH2B data (ref. 10) are for the same model in the same tunnel with a distributed roughness of 0.002 inches over most of the windward surface. The AEDC - MH-11 data are for the present test described briefly above with a distributed roughness of 0.001 in. and no discrete roughness elements. The NASA LaRC data are from the test also described above with a smooth surface model. The STS-2 data were derived from flight thermocouple data for the Orbiter Columbia which has a nominal distributed roughness of 0.060 in. and experienced a nominal transition (Mach $~ 8$ and $\operatorname{Re}_{\mathrm{L}} \sim 8.5$ million). The Orbiter Endeavor, which has an estimated $0.050 \mathrm{in.} \mathrm{nominal} \mathrm{distributed} \mathrm{roughness,} \mathrm{flew} \mathrm{STS-}$ 54 and experienced transition slightly earlier than normal (Mach 7 - 7.5).

As would be expected, the models with the distributed roughness account for the lowest transition parameter values, Reo $/ \mathrm{M}_{\mathrm{e}}$, with no discemible difference between the 0.001 and 0.002 in. distributed roughness results. The NASA LaRC smooth-body data are another level higher than the AEDC data. This result may be due to differences in tunnel noise. The AEDC tests were conducted with the model insertion door open which may introduce additional noise into the tunnel. The flight data is another level higher than the wind tunnel data. Again, this may be a result of tunnel noise affecting the transition process on a smooth model. The STS-54 data are at about the same level or slightly lower than the STS-2 values contrary to transition occurring later in night. This discrepancy may be due to the different methods used in computing $\operatorname{Re} \theta / M_{e}$. The STS-54 values came from

Ref. 1. Note that wind tunnel and flight data presented here tend to fall along similarly shaped curves that deviate from the original smooth-body correlation presented in Fig. 11. Figure 12b provides $\operatorname{Re} \theta$ at which transition occurs on the Orbiter centertine. Note that $\operatorname{Re}_{\theta} / \mathrm{Me}_{e}$ collapses the differences between the flight data and wind tunnel data better than $\operatorname{Re} \theta$. This result may be due to the differences in the edge Mach numbers between flight and the wind tunnel (see Fig. 4).

Isolated Roughness Elements.

Given roughness-induced transition data from ground tests and from flight data, the problem becomes how to compare the results. Typically, a transition correlation is desired such that future transition events can be predicted and such that past events can be understood. The usual path is to choose a transition parameter and a disturbance parameter and to find a functional relationship between the two. This process is complicated when many different physical phenomena that affect transition are present in the set of data being correlated. For a winged reentry vehicle like the Orbiter, these phenomena include heat transfer, streamwise and lateral pressure gradients, and boundary-layer cross flow. Since the available set of data include wind tunnel data with different wall temperatures, flight data with the high heating of reentry, and data for various locations on the Orbiter where the pressure gradients are significantly different, the process of developing a single transition correlation becomes very difficult.

To begin the correlation process, the transition parameter, Rea $/ \mathrm{M}_{e}$, as used for the smooth and distributed roughness data, has been chosen. Candidate disturbance parameters include the roughness Reynolds number, $\mathrm{Re}_{\mathrm{k}}$, and the roughness height ratioed by a characteristic dimension of the boundary layer $-\mathrm{k} / \delta, \mathrm{k} / \theta$, or $\mathrm{k} / \delta^{*}$. Figures $13-16$ present the results for the combined wind tunnel and flight discreteroughness transition data. For an acceptable correlation, one should expect to observe a clear trend in which the transition parameter decreases as the disturbance parameter increases. $\mathrm{Re}_{\mathrm{k}}$, Fig. 13, provides no clear trend. Using $\mathrm{k} / \delta$ or $\mathrm{k} / \theta$, Fig. 14 and 15 , respectively, results in the desired trend despite a lot of scatter in the data. The LaRC data by themselves show a clear trend but the AEDC data are scattered on both sides of the LaRC data. In both cases, the flight data lie above the wind tunnel results. Referring to Table I, one can determine that for the AEDC warm-wall data, the off-centerline results tend to lie above the LaRC data and the on-centerline values lie below the LaRC values. The separation of the oncenterline and off-centerline data may be due to cross-flow effects. The AEDC cold-wall data exhibit significant scatter. Using $\mathrm{k}^{/ \delta^{*}}$ as the disturbance parameter, Fig. 16, appears to collapse the data better and a more obvious trend for the cold-wall data develops. This result suggests that the data should be corrected for heat transfer effects.

In order to account for some of the known effects on transition, two roughness-induced transition correlations for blunt bodies have been chosen for evaluation with the existing set of Orbiter data - the PANT correlation (ref. 19) and the Van Driest/Blumer correlation (ref. 20). Both 
correlations were developed for transition on the nose of a sphencal nose cap on an axisymmetric body and include corrections for heat transfer and for pressure gradient. The PANT correlation uses the edge-to-wall temperature ratio to correct the disturbance parameter and the Van Driest/Blumer correlation uses an isentropic edge-to-wall temperature ratio to correct the transition parameter. The pressure gradient correction for both correlations is based upon the ratio of the roughness height to the nose radius $-1+350 \mathrm{k} / \mathrm{R}_{\mathrm{n}}$. For the

Orbiter this correction is not usable since it does not have a constant radius nose and since the data were obtained at many locations off the nose region. Therefore, a new pressure gradient correction term was defined $-1+B / B_{S}$ where $B$ is the streamwise velocity gradient at the edge of the boundary layer computed by the BLIMP code. $B_{S}$ is the value at the stagnation point and that value is 0.5 .

The PANT correlation uses $\operatorname{Re}_{\theta}$ for the transition parameter and $k / \theta$ for the disturbance parameter. The transition parameter has been changed to Reg/Me to account for differences in edge Mach number, as seen in Fig. 4., and the results are presented in Figure 17. With the aforementioned correction terms, the wind tunnel data tend to follow the expected trend as shown by the curve-fit in Fig. 17 with a scatter of approximately $\pm 35 \%$ (all but 2 data points). However, the flight data lie $54 \%$ and $67 \%$ (STS-28 and STS73 , respectively) above the wind tunnel curve-fit. Note that the pressure gradient correction parameter made little difference in the correlation but the $\mathrm{T}_{e} \mathrm{~T}_{\mathrm{W}}$ correction had a more significant impact. The Van Driest/Blumer correlation uses $\operatorname{Re} \delta^{*}$ for the transition parameter and $\mathrm{k} / \delta^{*}$ for the disturbance parameter. The present data set using these parameters are presented in Figure 18. The wind tunnel data are not correlated as well with a $\pm 65 \%$ uncertainty band required to cover all but 2 data points. The flight data lie $69 \%$ for STS-28 and $208 \%$ for STS- 73 above the curve-fit.

Both modified correlations appear to represent the data fairly well despite predicting an earlier transition than indicated by the flight data. However, the uncertainty in the exact roughness height during flight may contribute to this discrepancy. Also, recall that neither correlation directly accounts for the differences in cross-flow due to some elements being on centerline - no cross-flow - and for some elements being near the attachment line where the cross-flow is significant. Furthermore, the pressure gradient correction considers only the streamwise component. The roughness elements near the nose experience significant pressure gradients in both the streamwise and transverse directions.

\section{Conclusions}

Orbiter smooth-body and distributed-roughness wind tunnel transition data have been compared to nominal flight boundary-layer transition data and it has been determined that in flight, Orbiter boundary-layer transition nominally occurs at $\operatorname{Re} \theta \mathrm{M}_{\mathrm{e}}$ values 25 to $60 \%$ higher than the available wind tunnel data. This result is probably due to the effects of wind tunnel noise. The results of isolated-roughness induced transition wind tunnel tests have been compared to two Orbiter flight cases using two existing transition correlations that account for heat transfer and pressure gradient effects. Despite the use of two different wind tunnels, two different scale wind tunnel models, and two different shaped roughness elements, the wind tunnel data are correlated within $\pm 35 \%$ by the modified PANT correlation. The flight test data follow the same trends as the wind tunnel data but are higher resulting in transition later than would be predicted by the wind tunnel data. This result may be due to the significant uncertainty in the roughness height during flight. Nevertheless, these data show that a single roughness element that is 15 to $40 \%$ of the boundary-layer thickness can cause early transition on the Space Shuttle Orbiter. The data provided by this investigation and the data reduction methods will hopefully assist in the prediction of transition due to discrete-roughness elements on future winged reentry vehicles.

\section{Acknowledgements}

The authors would like to thank Jeremy Jacobs/N. Dakota State University for compiling the smooth-body transition data from the various test reports.

\section{References}

1. Bouslog, S.A., An, M.Y., and Derry, S.M., "Orbiter Windward-Surface Boundary-Layer Transition Flight Data," NASA CP 3248, Orbiter Experiments Aerothermodynamic Symposium, April 1995.

2. Reshotko, E, "Boundary Layer Instability, Transition, and Control," AIAA 94-0001, 32nd AIAA Aerospace Sciences Meeting, Jan. 10-13, 1994.

3. Stetson, K. F., "Hypersonic Boundary-Layer Transition," Adyances in Hypersonics. Vol. I Birkhauser Boston, Boston, MA, 1992, J. Bertin, J. Periaux, and J. Ballmann (Eds.), pp. 324-417.

4. Romere, P. O., Campbell, C. H., Caram, J. M., and Bouslog, S. A., "Results of the 0.0175-Scale Shuttle Orbiter Vehicle Boundary Layer Transition Wind Tunnel Test (MH-11) in the AEDC VKF Tunnel B," NASA TM 104820, May, 1996.

5. Bertin, J.J., Stetson, K.F., Bouslog, S.A., and Caram, J.M., "Effect of Isolated Roughness Elements on 
Boundary-Layer Transition for Shuttle Orbiter," AlAA Paper 96-1906, 3 1st AIAA Thermophysics Conference, June 1996.

6. Berry, S. A., Bouslog, S. A., Brauckmann, G. J., and Caram, J. M.," Experimental Investigation of BoundaryLayer Transition on the Shuttle Orbiter in the LaRC 20Inch Mach 6 Tunnel," AlAA 97-0273, 35th Aerospace Sciences Meeting, Jan. 1997.

7. Goodrich, W. D., Derry, S. M., and Bertin, J. J., "Shuttle Orbiter Boundary-Layer Transition at Flight and Wind Tunnel Conditions, "Shuttle Performance: Lessons Learned, Part 2, NASA CP 2283, March 1983, pp. 753779.

8. --, "Orbiter Entry Heating Prediction Methods and Data Base," STS83-0948, Rev. I, Rockwell internationai Space Transportation \& Systems Grotp, Downey, CA; July 1938.

9. Marincale, W F. and Trmer, L. L., "Test Results from the NASA/Rocikwell International Space Shuttle Test (MH4A) Conducted in the AEDC VKF Tunnel B," AEDC-DR-74-39, AEDC, May 1974.

10. Siler, L. G. and Martindale, W. R., "Test Results from the NASA Space Shuttle Orbiter Heating Test (MH-2) Conducted in the AEDC VKF Tunnel B," AEDC-DR75-103, AEDC, Oct. 1975.

11. Wannenwetsch, W. D. and Martindale, W. R., "Roughness and Wall Temperature Effects on Boundary-Layer Transition on a 0.0175-Scale Space Shuttle Orbiter Tested at Mach Number 8, " AEDC-TR77-19, AEDC, April 1977.

12. An, M.Y., Wang, K.C., and Tam, L.T., " Computation of Inviscid Flow field Around 3-D Aerospace Vehicles and Comparison with Experimental \& Fight Data," AlAA Paper 93-0885, Reno, NV, Jan. 1993.

13. An, M.Y., Wang, K.C., Campbell, C.H., and Pelley, R. L., "Space Shuttle Orbiter Aerodynamics Induced by Asymmetric Boundary-Layer Transition," AIAA 960808, Jan. 15-18, 1996.

14. Wang. K.C., "An Axisymmetric Analog Two-Layer Convective Heating Procedure with Application to the Evaluation of Space Shuttle Orbiter Wing Leading Edge and Windward Surface Heating, " NASA CR 188343, Sept. 1994.

15. Murray, A.L., "Further Enhancements of the BLIMP Computer Code and User's Guide," AFWAL-TR-3010, Wright-Patterson Air Force Base, OH, June 30, 1988.

16. Kolodziej, P. and Stewart, D. A., "Nitrogen Recombination on High-Temperature Reusable Surface Insulation and its Effect on Surface Catalysis," AlAA87.1637, June 1987.

17. Gnoffo, P. and Weilmuenster, K.A., "Multiblock Analysis for Shuttle Orbiter Reentry Heating from Mach 24 to Mach 12," AIAA Paper 93-2813, Orlando, FL, July 6-9, 1993.

18. Bertin, J. J., Hayden, T. E, and Goodrich, W. D.,
"Shuttle Boundary-Layer Transition Due to Distributed Roughness and Surface Cooling, " Joumal of Spacecraft and Rockets, Vol. 19, No. 5, Sept. - Oct. 1982, pp. 389396.

19. Batt, R.G. and Legner, H.H., "A Review of RoughnessInduced Nose tip Transition," AlAA Joumal, Vol. 21, No. 1, January 1983, pp. 7 - 22.

20. van Driest, ER. and Blumer, C.B., "Boundary-Layer Transition on Blunt Bodies - Effect of Roughness," AIAA Journal, Vol. 5, No. 10, Oct. 1967, pp. 1913 . 1915. 
Table I - AEDC Transition Test Results.

(a) Centerline, Alpha $=40^{\circ}, \mathrm{T}_{\mathrm{w}}=540^{\circ} \mathrm{R}$

$\begin{array}{lllllllllllll}\text { Roughness } & \operatorname{Re} / f t & (\mathrm{X} / \mathrm{L})_{\mathrm{t}} & \text { B } & \mathrm{T}_{\mathrm{e}} \mathrm{T}_{\mathrm{w}} & \operatorname{Re} \delta^{*} & \operatorname{Re} \theta & \mathrm{M}_{\mathrm{e}} & \operatorname{Re} \theta / \mathrm{M}_{\mathrm{e}} & \operatorname{Re}_{\mathrm{k}} & \mathrm{k} / \delta^{*} & \mathrm{k} / \boldsymbol{\theta} & \mathrm{k} / \delta\end{array}$ Element $(x 106)$

\begin{tabular}{|l|c|c|c|c|c|c|c|c|c|c|c|c|}
\hline $\begin{array}{l}\mathrm{A}-2 \\
\mathrm{k}=0.004\end{array}$ & 2.25 & 0.05 & 0.22 & 2.17 & 71 & 75 & 0.85 & 87 & 178 & 2.35 & 2.22 & 0.23 \\
\hline $\begin{array}{l}\mathrm{A}-3 \\
\mathrm{k}=0.008 \text { in }\end{array}$ & 1.75 & 0.05 & 0.22 & 2.14 & 61 & 66 & 0.85 & 77 & 280 & 4.32 & 4 & 0.4 \\
\hline $\begin{array}{l}\mathrm{D}-3 \\
\mathrm{k}=0.008 \text { in }\end{array}$ & 1.5 & 0.09 & 0.17 & 1.98 & 108 & 92 & 1.07 & 87 & 260 & 2.35 & 2.76 & 0.27 \\
\hline $\begin{array}{l}\mathrm{G}-2 \\
\mathrm{k}=0.006 \text { in }\end{array}$ & 1.35 & 0.375 & 0.1 & 1.6 & 365 & 210 & 1.56 & 135 & 158 & 0.72 & 1.25 & 0.12 \\
\hline $\begin{array}{l}\mathrm{G}-3 \\
\mathrm{k}=0.015 \text { in }\end{array}$ & 0.82 & 0.375 & 0.1 & 1.55 & 279 & 163 & 1.6 & 104 & 310 & 1.4 & 2.4 & 0.22 \\
\hline $\begin{array}{l}\mathrm{J}-2 \\
\mathrm{k}=0.010 \text { in }\end{array}$ & 1.25 & 0.575 & 0.09 & 1.48 & 558 & 282 & 1.76 & 160 & 310 & 0.91 & 1.8 & 0.16 \\
\hline
\end{tabular}

(b) Centerline, Alpha $=40^{\circ}, \mathrm{T}_{\mathrm{w}}=200^{\circ} \mathrm{R}$

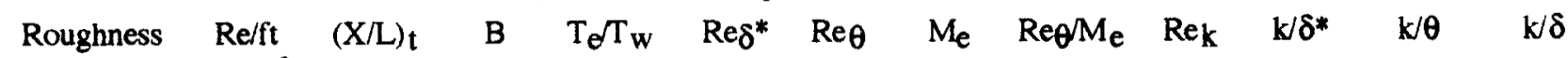
Element $\left(\mathrm{x} 10^{6}\right)$

\begin{tabular}{|l|c|c|c|c|c|c|c|c|c|c|c|c|}
\hline $\begin{array}{l}\mathrm{A}-3 \\
\mathrm{k}=0.008 \text { in }\end{array}$ & 1.75 & 0.05 & 0.22 & 5.79 & 10 & 72 & 0.85 & 83 & 285 & 26.7 & 3.64 & 0.4 \\
\hline $\begin{array}{l}\mathrm{D}-3 \\
\mathrm{k}=0.008 \text { in }\end{array}$ & 1.5 & 0.09 & 0.17 & 5.34 & 24 & 99 & 1.07 & 92 & 300 & 10.7 & 2.58 & 0.28 \\
\hline $\begin{array}{l}\mathrm{G}-3 \\
\mathrm{k}=0.015 \text { in }\end{array}$ & 0.62 & 0.375 & 0.1 & 4.19 & 102 & 160 & 1.6 & 98 & 350 & 3.3 & 2.1 & 0.21 \\
\hline $\begin{array}{l}\mathrm{J}-2 \\
\mathrm{k}=0.010 \text { in }\end{array}$ & 0.62 & 0.575 & 0.09 & 3.9 & 164 & 218 & 1.78 & 122 & 265 & 1.6 & 1.2 & 0.12 \\
\hline
\end{tabular}

(c) Centerline, Alpha $=35^{\circ}, \mathrm{T}_{\mathrm{W}}=540^{\circ} \mathrm{R}$

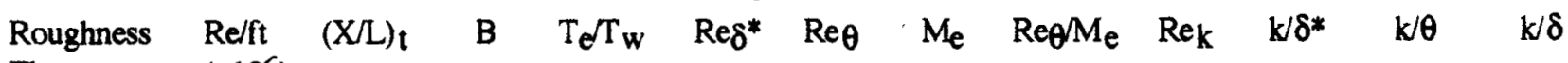
Element $\left(x 10^{6}\right)$

\begin{tabular}{|l|c|c|c|c|c|c|c|c|c|c|c|c|}
\hline $\begin{array}{l}\mathrm{G}-3 \\
\mathrm{k}=0.015 \text { in }\end{array}$ & 0.82 & 0.375 & 0.09 & 1.32 & 415 & 178 & 1.98 & 90 & 340 & 1.2 & 2.8 & 0.24 \\
\hline $\begin{array}{l}\mathrm{J}-2 \\
\mathrm{k}=0.010 \text { in }\end{array}$ & 1.25 & 0.575 & 0.08 & 1.23 & 811 & 312 & 2.17 & 145 & 300 & 0.8 & 2.08 & 0.18 \\
\hline
\end{tabular}

(d) Centerline, Alpha $=35^{\circ}, \mathrm{T}_{\mathrm{W}}=200^{\circ} \mathrm{R}$

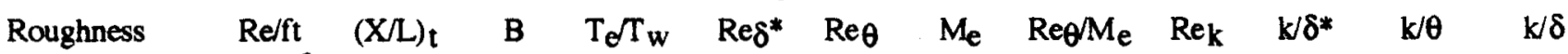
Element (x106)

\begin{tabular}{|l|c|c|c|c|c|c|c|c|c|c|c|c|}
\hline $\begin{array}{l}\mathrm{D}-3 \\
\mathrm{k}=0.008 \text { in }\end{array}$ & 1 & 0.09 & 0.17 & 4.78 & 33 & 90 & 1.27 & 71 & 220 & 5.8 & 2.1 & 0.22 \\
\hline $\begin{array}{l}\mathrm{G}-3 \\
\mathrm{k}=0.015 \text { in }\end{array}$ & 0.62 & 0.375 & 0.09 & 3.56 & 152 & 165 & 1.94 & 85 & 390 & 2.5 & 2.3 & 0.23 \\
\hline $\begin{array}{l}\mathrm{J}-2 \\
\mathrm{k}=0.010 \text { in }\end{array}$ & 0.62 & 0.575 & 0.08 & 3.25 & 274 & 235 & 2.18 & 108 & 275 & 1.2 & 1.4 & 0.14 \\
\hline
\end{tabular}


Table I - Concluded.

(e) Off-Centerline, Alpha $=40^{\circ}, \mathrm{T}_{\mathrm{w}}=540^{\circ} \mathrm{R}$

$\begin{array}{llllllllllll}\text { Roughness } & \operatorname{Re} / \mathrm{ft} & (\mathrm{X} / \mathrm{L})_{\mathrm{t}} & \mathrm{B} & \mathrm{T}_{\mathrm{e}} / \mathrm{T}_{\mathrm{w}} & \operatorname{Re} \delta^{*} & \operatorname{Re} \theta & \mathrm{M}_{\mathrm{e}} & \operatorname{Re} \theta / M_{e} & \operatorname{Re} k \quad k / \delta^{*} & k / \theta & k / \delta\end{array}$ Element $(x 106)$

\begin{tabular}{|l|c|c|c|c|c|c|c|c|c|c|c|c|}
\hline $\begin{array}{l}\mathrm{C}-3 \\
\mathrm{k}=0.008 \text { in }\end{array}$ & 1.75 & 0.07 & 0.16 & 2.05 & 88 & 85 & 0.99 & 86 & 300 & 3.2 & 3.3 & 0.33 \\
\hline $\begin{array}{l}\mathrm{C}-4 \\
\mathrm{k}=0.015 \text { in }\end{array}$ & 1.75 & 0.07 & 0.16 & 2.05 & 89 & 85 & 0.99 & 86 & 555 & 6 & 6.25 & 0.62 \\
\hline $\begin{array}{l}\mathrm{F}-3 \\
\mathrm{k}=0.015 \text { in }\end{array}$ & 1.5 & 0.26 & 0.07 & 1.69 & 277 & 170 & 1.5 & 113 & 590 & 2.3 & 3.75 & 0.34 \\
\hline $\begin{array}{l}\mathrm{I}-2 \\
\mathrm{k}=0.006 \text { in }\end{array}$ & 2.25 & 0.375 & 0.09 & 1.64 & 445 & 258 & 1.59 & 163 & 310 & 1.02 & 1.76 & 0.16 \\
\hline $\begin{array}{l}\mathrm{K}-3 \\
\mathrm{k}=0.008 \text { in }\end{array}$ & 1 & 0.62 & -0.02 & 1.4 & 441 & 190 & 1.77 & 108 & 190 & 0.84 & 1.95 & 0.17 \\
\hline
\end{tabular}

(f) Off-Centerline, Alpha $=40^{\circ}, \mathrm{T}_{\mathrm{w}}=200^{\circ} \mathrm{R}$

$\begin{array}{llllllllllll}\text { Roughness } & \operatorname{Re} / f t & (X / L)_{t} & B & T_{e} / T_{W} & \operatorname{Re} \delta^{*} & \operatorname{Re} \theta \quad M_{e} & \operatorname{Re} \theta M_{e} & \operatorname{Re}_{k} \quad k / \delta^{*} \quad k / \theta \quad k / \delta\end{array}$ Element $(x 106)$

\begin{tabular}{|l|c|c|c|c|c|c|c|c|c|c|c|c|}
\hline $\begin{array}{l}\mathrm{I}-2 \\
\mathrm{k}=0.006 \text { in }\end{array}$ & 2.25 & 0.375 & 0.09 & 4.37 & 154 & 243 & 1.63 & 149 & 390 & 2.31 & 1.46 & 0.15 \\
\hline $\begin{array}{l}\mathrm{K}-3 \\
\mathrm{k}=0.008 \text { in }\end{array}$ & 1 & 0.62 & -0.02 & 3.77 & 121 & 165 & 1.88 & 88 & 220 & 1.5 & 1.1 & 0.14 \\
\hline
\end{tabular}

(g) Off-Centerline, Alpha $=35^{\circ}, \mathrm{T}_{\mathrm{W}}=540^{\circ} \mathrm{R}$

\begin{tabular}{|c|c|c|c|c|c|c|c|c|c|c|c|c|}
\hline $\begin{array}{l}\text { Roughness } \\
\text { Element }\end{array}$ & $\begin{array}{l}\mathrm{Re} / \mathrm{ft} \\
\left(\mathrm{x} 10^{6}\right)\end{array}$ & $(\mathrm{X} / \mathrm{L})_{\mathrm{t}}$ & B & $\mathrm{T}_{\mathbf{e}} \mathrm{TT}_{\mathbf{w}}$ & $\operatorname{Re} \delta^{*}$ & $\operatorname{Re} \theta$ & $\mathrm{Me}_{\mathrm{e}}$ & $\operatorname{Re}_{\theta} M_{e}$ & $\operatorname{Re}_{k}$ & $\mathrm{k} / \delta^{*}$ & $k / \theta$ & $\mathrm{k} / \delta$ \\
\hline $\begin{array}{l}C-3 \\
k=0.008 \text { in }\end{array}$ & 1.75 & 0.07 & 0.18 & 1.93 & 108 & 93 & 1.16 & 80 & 310 & 2.86 & 3.33 & 0.33 \\
\hline $\begin{array}{l}C-4 \\
k=0.015 \text { in }\end{array}$ & 1.5 & 0.07 & 0.18 & 1.91 & 101 & 85 & 1.15 & 74 & 510 & 4.84 & 5.77 & 0.56 \\
\hline $\begin{array}{l}F-3 \\
k=0.015 \text { in }\end{array}$ & 1.88 & 0.26 & 0.09 & 1.5 & 389 & 210 & 1.82 & 115 & 850 & 2.38 & 4.41 & 0.41 \\
\hline $\begin{array}{l}\mathrm{K}-3 \\
\mathrm{k}=0.008 \text { in }\end{array}$ & 1.15 & 0.62 & -0.02 & 1.16 & 531 & 250 & 2.25 & 111 & 270 & 0.8 & 1.7 & 0.19 \\
\hline
\end{tabular}

(h) Off-Centerline, Alpha $=35^{\circ}, \mathrm{T}_{\mathrm{W}}=200^{\circ} \mathrm{R}$

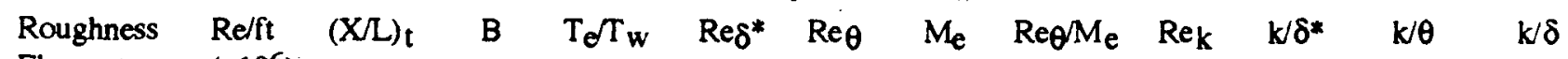
Element $(x 106)$

\begin{tabular}{|l|c|c|c|c|c|c|c|c|c|c|c|c|}
\hline $\begin{array}{l}\mathrm{C}-3 \\
\mathrm{k}=0.008 \text { in }\end{array}$ & 1.5 & 0.07 & 0.18 & 5.15 & 26 & 95 & 1.18 & 80 & 305 & 10.7 & 2.9 & 0.3 \\
\hline $\begin{array}{l}\mathrm{K}-3 \\
\mathrm{k}=0.008 \text { in }\end{array}$ & 0.62 & 0.62 & -0.02 & 3.1 & 276 & 195 & 2.26 & 86 & 248 & 1.18 & 1.67 & 0.15 \\
\hline
\end{tabular}


Table II - NASA-LaRC Transition Test Results.

Alpha $=40^{\circ}, T_{W}=540^{\circ} \mathrm{R}$

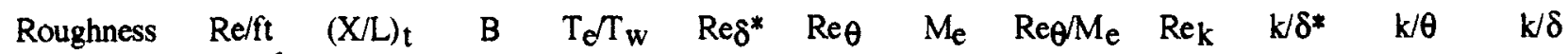
Element $(x 106)$

\begin{tabular}{|c|c|c|c|c|c|c|c|c|c|c|c|c|}
\hline $\begin{array}{l}B \\
k=0.005 \text { in }\end{array}$ & 2.2 & 0.07 & 0.19 & 1.39 & 118 & 69 & 1.01 & 70 & 292 & 2.57 & 4.38 & 0.4 \\
\hline $\begin{array}{l}D \\
k=0.0025 \text { in }\end{array}$ & 5.2 & 0.09 & 0.18 & 1.39 & 217 & 125 & 1.11 & 114 & 328 & 1.75 & 3.03 & 0.28 \\
\hline $\begin{array}{l}D \\
k=0.005 \text { in }\end{array}$ & 2.5 & 0.09 & 0.18 & 1.35 & 155 & 86 & 1.11 & 78 & 343 & 2.35 & 4.21 & 0.38 \\
\hline $\begin{array}{l}D \\
k=0.0075 \text { in }\end{array}$ & 1.6 & 0.09 & 0.18 & 1.31 & 127 & 69 & 1.11 & 62 & 334 & 2.75 & 5.08 & 0.46 \\
\hline $\begin{array}{l}D \\
k=0.010 \text { in }\end{array}$ & 1.35 & 0.09 & 0.18 & 1.31 & 117 & 63 & 1.11 & 58 & 394 & 3.33 & 6.19 & 0.55 \\
\hline $\begin{array}{l}D E \\
k=0.0025 \text { in }\end{array}$ & 5.4 & 0.174 & 0.15 & 1.25 & 398 & 193 & 1.37 & 141 & 309 & 1.16 & 2.4 & 0.21 \\
\hline $\begin{array}{l}\mathrm{DE} \\
\mathrm{k}=0.005 \text { in }\end{array}$ & 2.7 & 0.174 & 0.15 & 1.22 & 289 & 136 & 1.37 & 100 & 371 & 1.6 & 3.4 & 0.3 \\
\hline $\begin{array}{l}D E \\
k=0.0075 \text { in }\end{array}$ & 1.9 & 0.174 & 0.15 & 1.2 & 247 & 114 & 1.37 & 82 & 415 & 1.97 & 4.29 & 0.37 \\
\hline $\begin{array}{l}D E \\
k=0.010 \text { in }\end{array}$ & 1.35 & 0.174 & 0.15 & 1.19 & 210 & 96 & 1.37 & 70 & 420 & 2.18 & 4.77 & 0.42 \\
\hline $\begin{array}{l}E C \\
k=0.0025 \text { in }\end{array}$ & 5 & 0.258 & 0.065 & 1.21 & 552 & 239 & 1.48 & 164 & 246 & 0.86 & 1.99 & 0.17 \\
\hline $\begin{array}{l}E C \\
k=0.005 \text { in }\end{array}$ & 2.8 & 0.258 & 0.065 & 1.17 & 425 & 178 & 1.48 & 119 & 352 & 1.25 & 2.98 & 0.26 \\
\hline $\begin{array}{l}E C \\
k=0.0075 \text { in }\end{array}$ & 1.8 & 0.258 & 0.065 & 1.14 & 348 & 143 & 1.48 & 98 & 379 & 1.47 & 3.6 & 0.31 \\
\hline $\begin{array}{l}G \\
k=0.0025 \text { in }\end{array}$ & 4.8 & 0.375 & 0.099 & 1.15 & 737 & 301 & 1.6 & 189 & 244 & 0.74 & 1.81 & 0.15 \\
\hline $\begin{array}{l}G \\
k=0.005 \text { in }\end{array}$ & 2.4 & 0.375 & 0.099 & 1.11 & 535 & 211 & 1.6 & 132 & 313 & 1.01 & 2.56 & 0.22 \\
\hline $\begin{array}{l}\mathrm{G} \\
\mathrm{k}=0.0075 \text { in }\end{array}$ & 1.85 & 0.375 & 0.099 & 1.09 & 481 & 185 & 1.6 & 117 & 422 & 1.31 & 3.39 & 0.29 \\
\hline
\end{tabular}

Table III - Flight Transition Results.

Alpha $\sim 40^{\circ}, T_{W}=$ Radiation Equilibrium

$\begin{array}{llllllllllll}\text { Roughness } & \operatorname{Re} / \mathrm{ft} & (\mathrm{X} / \mathrm{L})_{\mathrm{t}} & \mathrm{B} & \mathrm{T}_{\mathrm{e}} \mathrm{T}_{\mathrm{w}} & \operatorname{Re}^{*} & \operatorname{Re} \theta \quad \mathrm{M}_{\mathrm{e}} & \operatorname{Re} \theta / \mathrm{M}_{\mathrm{e}} & \operatorname{Re}_{\mathrm{k}} \quad \mathrm{k} / \delta^{*} & \mathrm{k} / \boldsymbol{\theta} & \mathrm{k} / \delta\end{array}$ Element

\begin{tabular}{|l|c|c|c|c|c|c|c|c|c|c|c|c|}
\hline $\begin{array}{l}\text { STS-28 } \\
k=0.25 \text { in }\end{array}$ & 0.233 & 0.407 & 0.07 & 3.45 & 464 & 412 & 2.83 & 146 & 494 & 1.41 & 1.59 & 0.14 \\
\hline $\begin{array}{l}\text { STS-73 } \\
\mathrm{k}=0.6 \text { in }\end{array}$ & 0.205 & 0.19 & 0.16 & 4.17 & 25 & 247 & 2.2 & 112 & 1044 & 32.6 & 3.35 & 0.34 \\
\hline
\end{tabular}




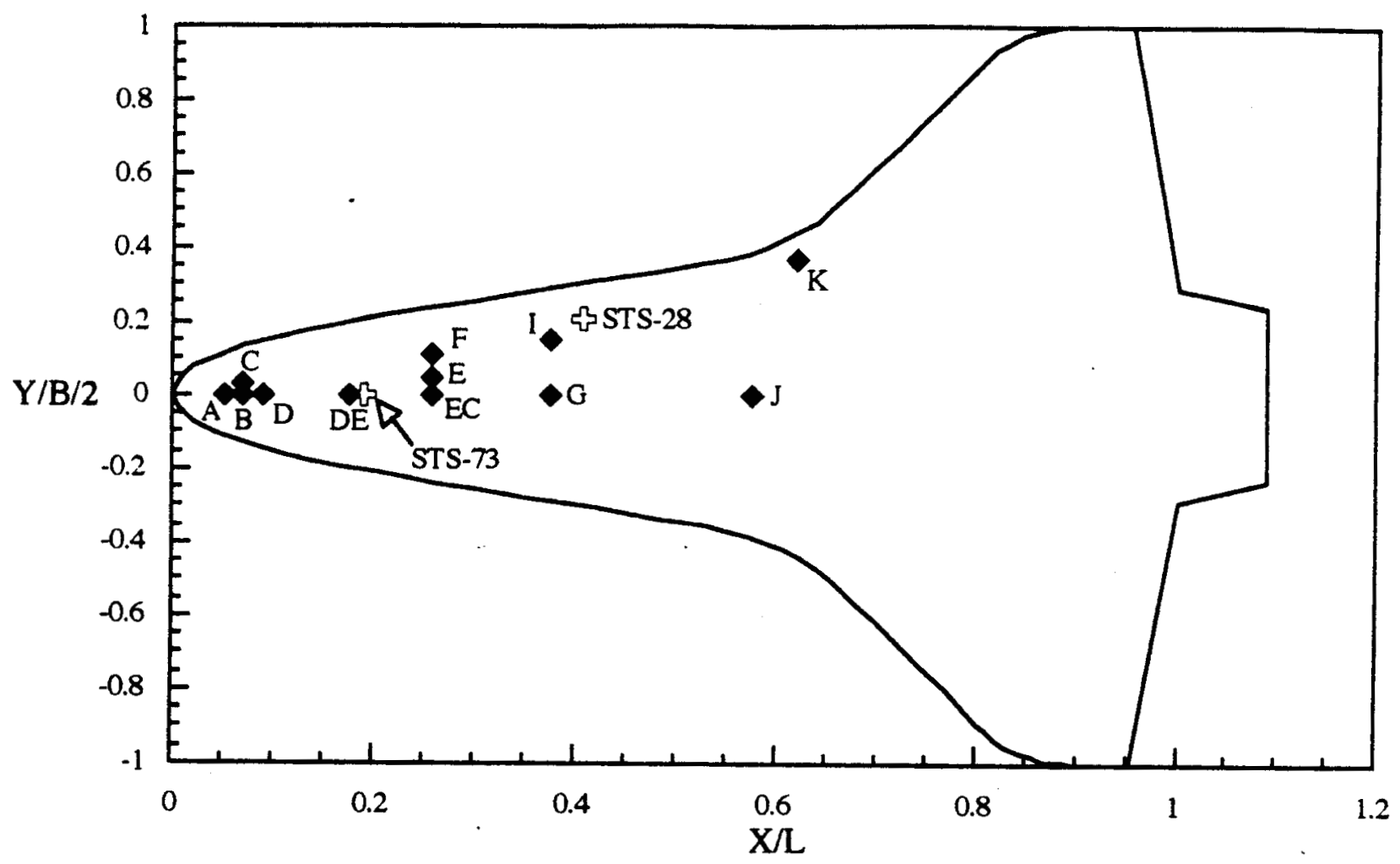

Figure 1 - Sketch of Orbiter Planform with Roughness Locations.
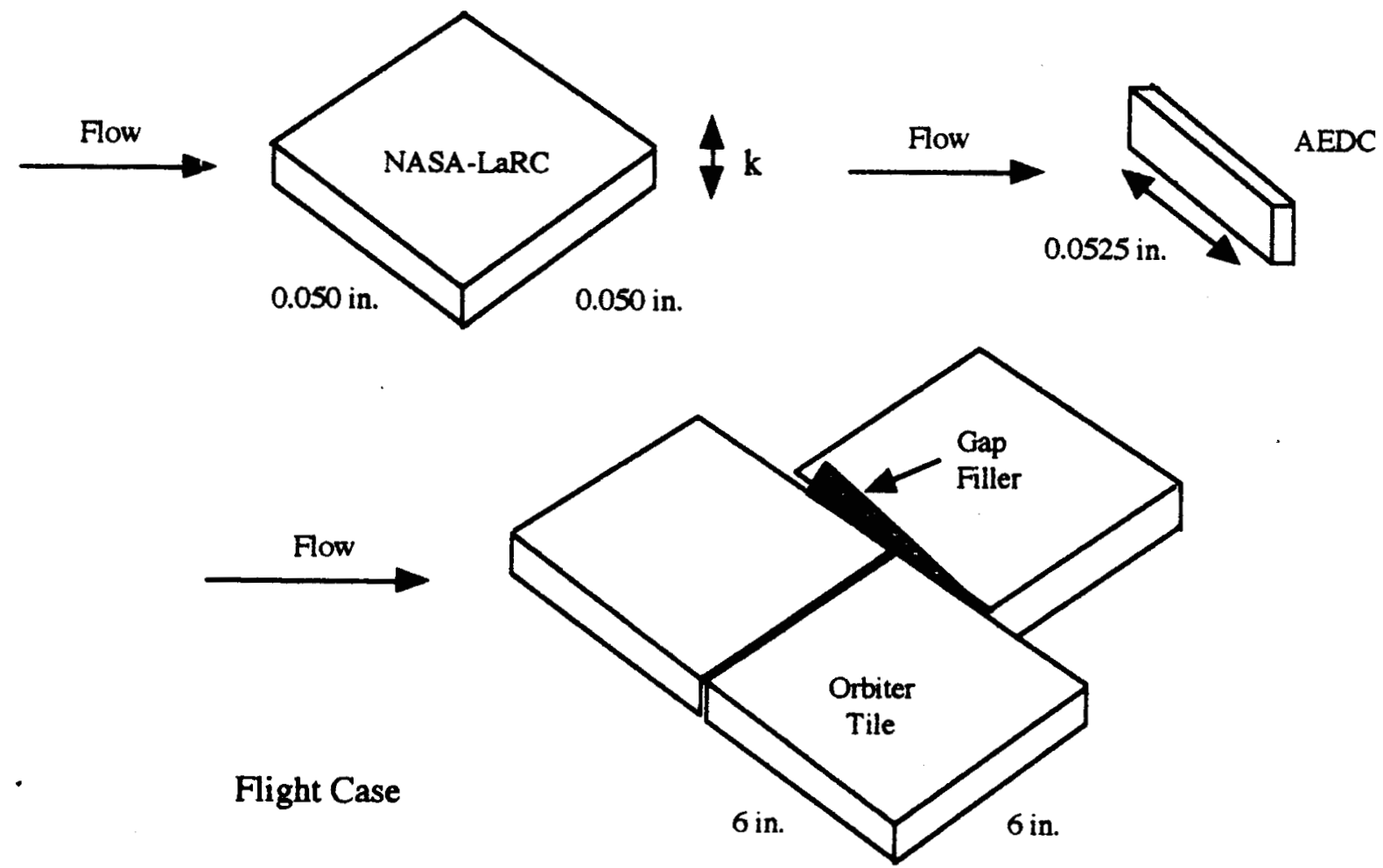

Figure 2 - Sketch of Roughness Elements. 


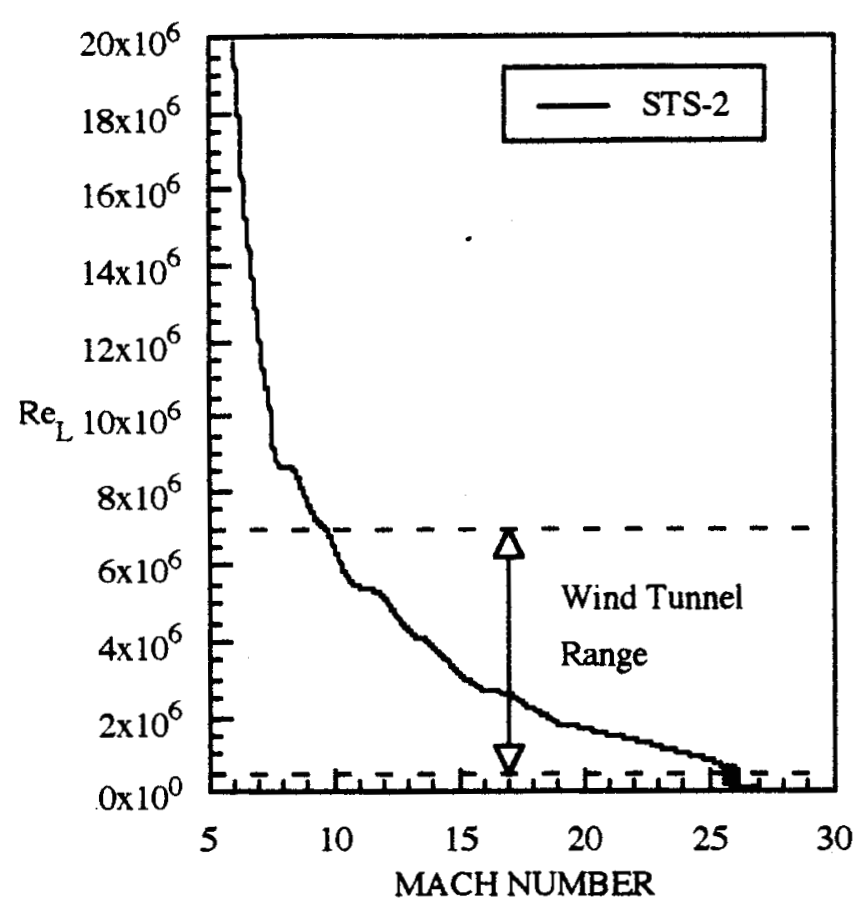

Figure 3 - Free stream Reynolds Number History for STS-2.

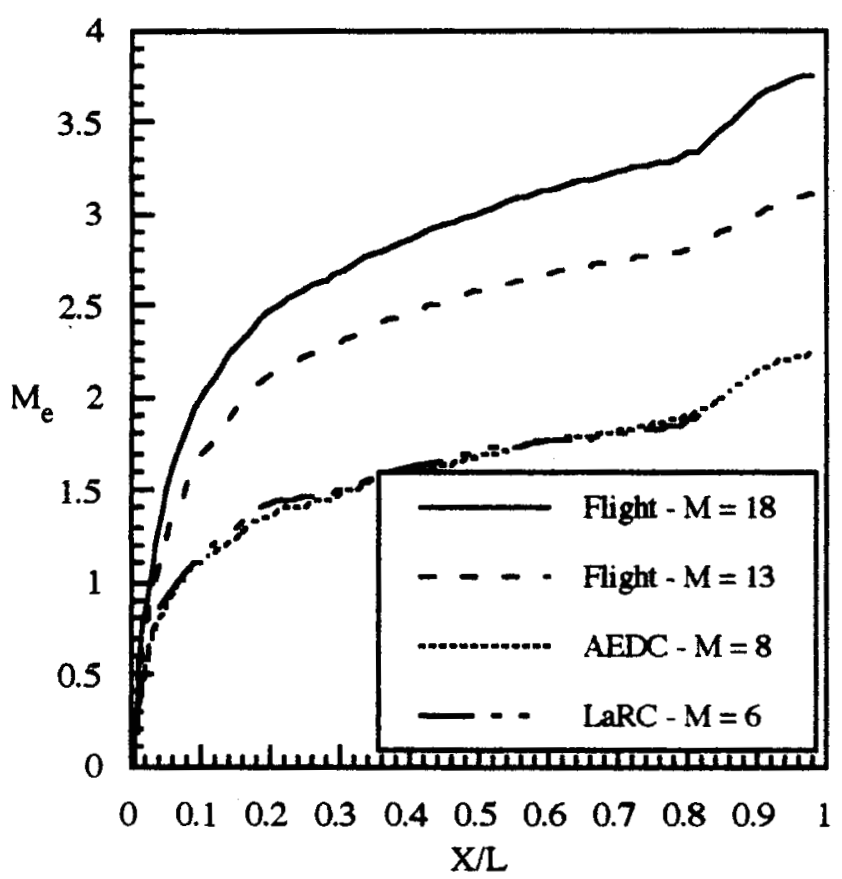

Figure 4 - Comparison of Local Mach Number along Orbiter Centerline for Alpha $\sim 40^{\circ}:$ Flt. $M=18-\operatorname{Re}_{\mathrm{L}}=2.5$ million; Flt. $M=13-\operatorname{Re}_{\mathrm{L}}=4.4$ million; $\mathrm{AEDC}-\mathrm{Re}_{\mathrm{L}}=1.88$ million; LaRC $-\operatorname{Re}_{\mathrm{L}}=1.78$ million.

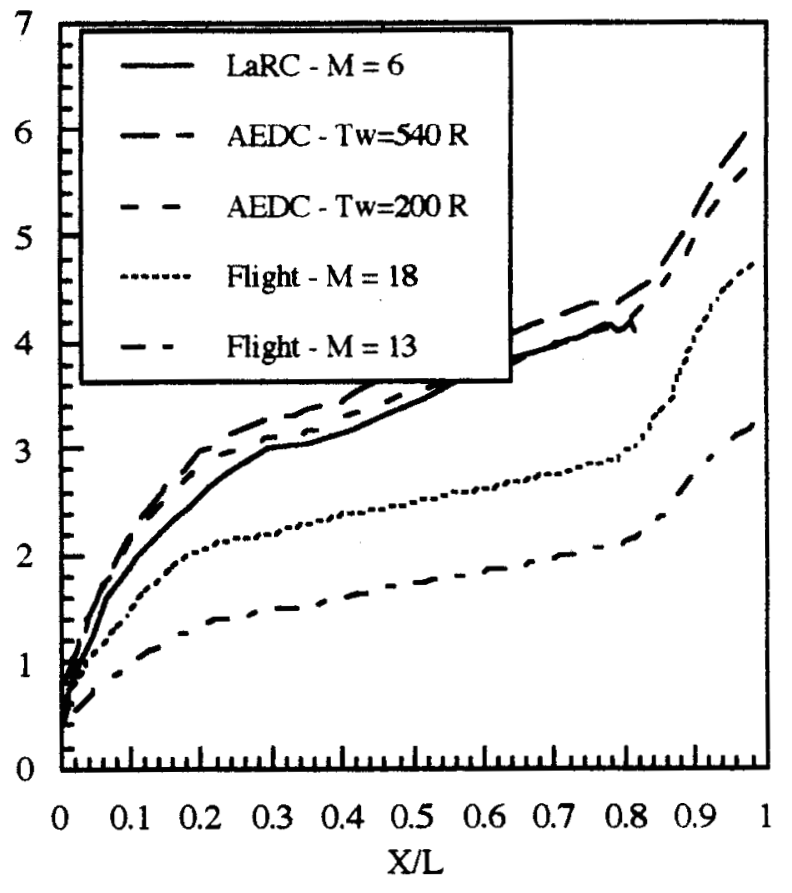

Figure 5 - Boundary-Layer Thickness Scaled by Model Scale along Orbiter Centerline for Alpha $\sim 40^{\circ}:$ Flt. $\mathrm{M}=18-\mathrm{Re}_{\mathrm{L}}$ $=2.5$ million; Flt. $M=13-\operatorname{Re}_{\mathrm{L}}=4.4$ million; $A E D C-\operatorname{Re}_{\mathrm{L}}$ $=1.88$ million; $\mathrm{LaRC}-\operatorname{Re}_{\mathrm{L}}=1.78$ million.

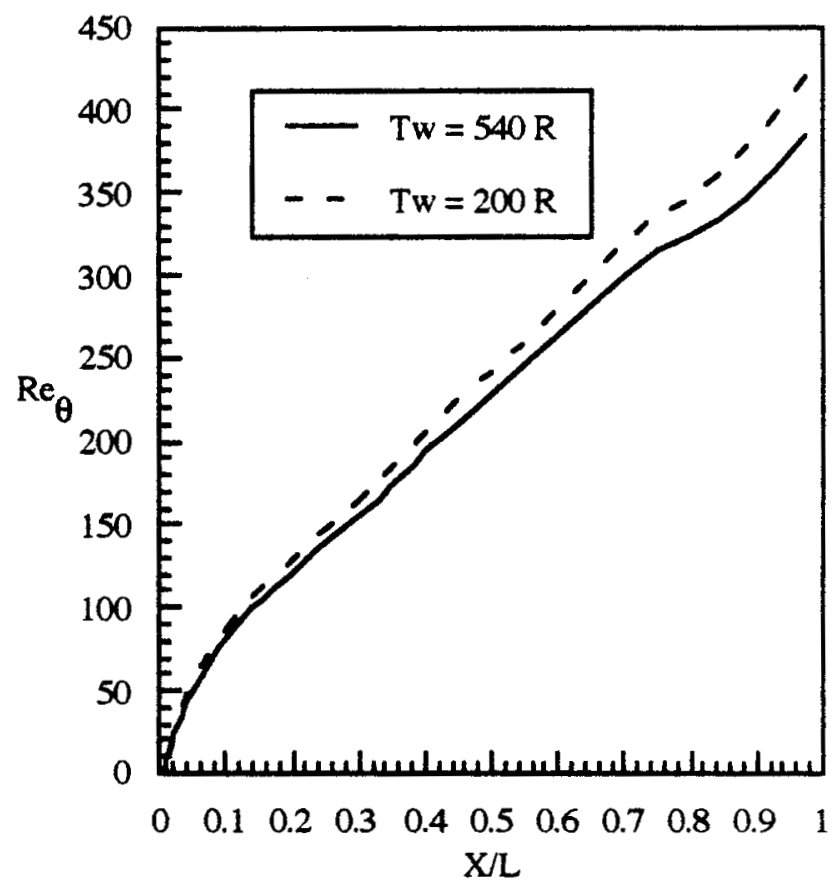

Figure 6 - Momentum Thickness Reynolds Number along AEDC Model at Re/ft $=1$ million for Alpha $=40^{\circ}$. 


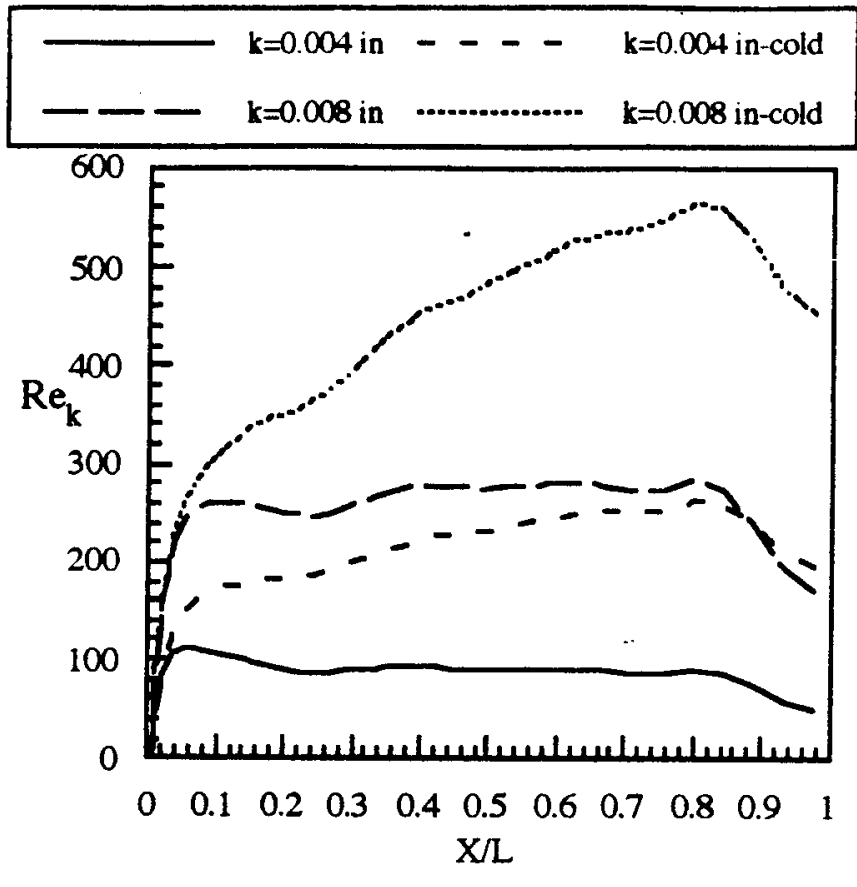

Figure 7 - Roughness Reynolds Number along AEDC Model Centerline for Alpha $=40^{\circ}$ and $\mathrm{Re} / \mathrm{ft}=1.5$ million.

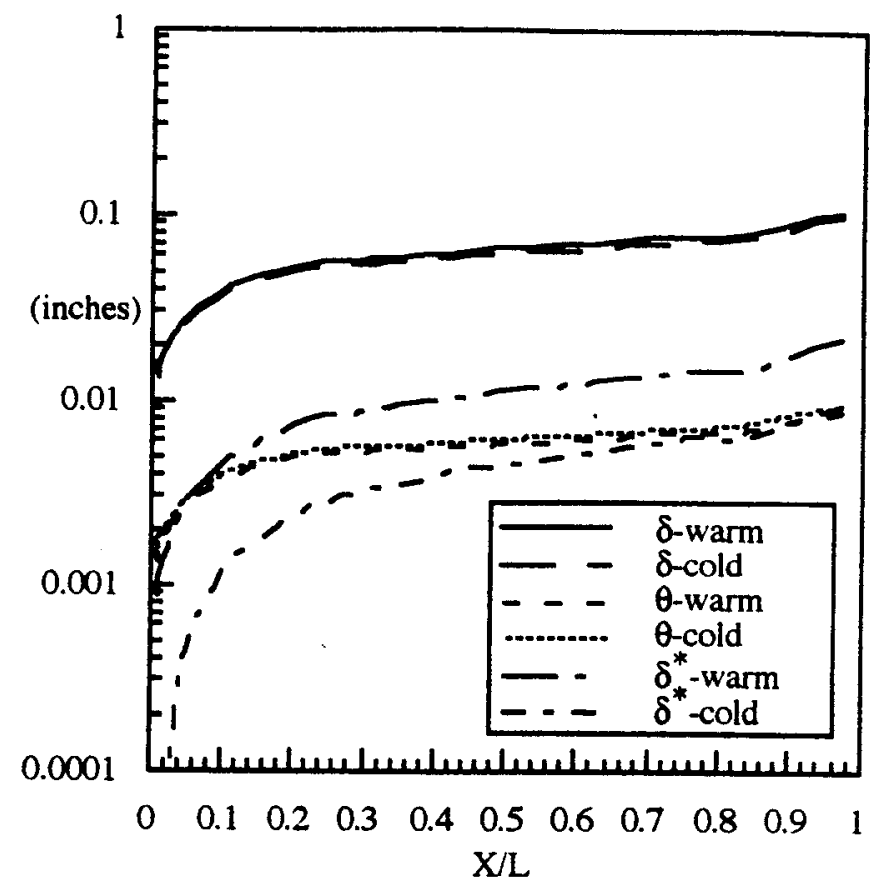

Figure 8 - Temperature Effects on Boundary Layer for AEDC Orbiter Model Centerline for Alpha $=40^{\circ}$ and $\operatorname{Re} / \mathrm{ft}$ $=1.0 \times 10^{6}$.

Note: Figures 9 and 10 are on the following page.

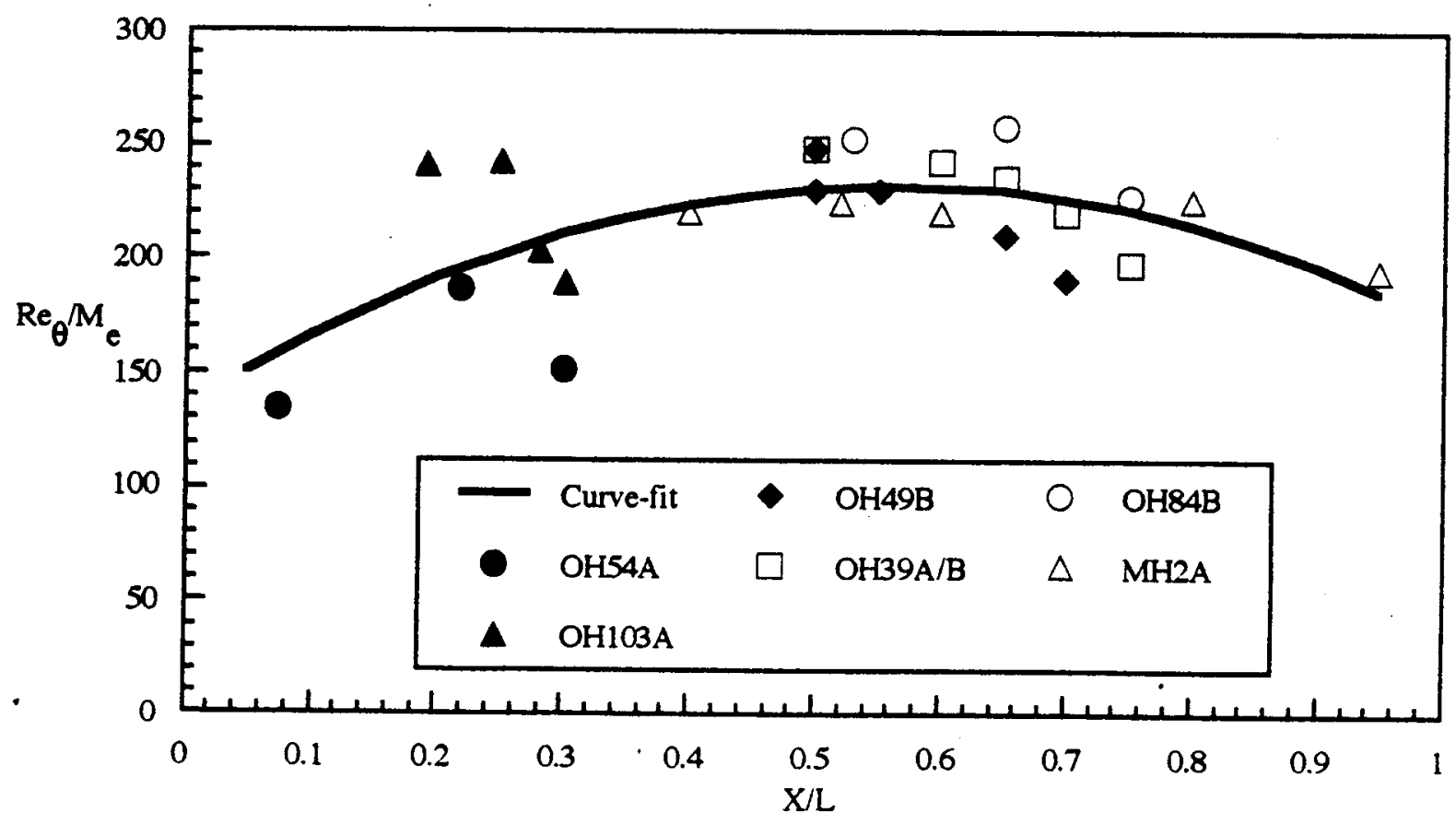

Figure 11 - Smooth-Body Orbiter Transition Correlation. 


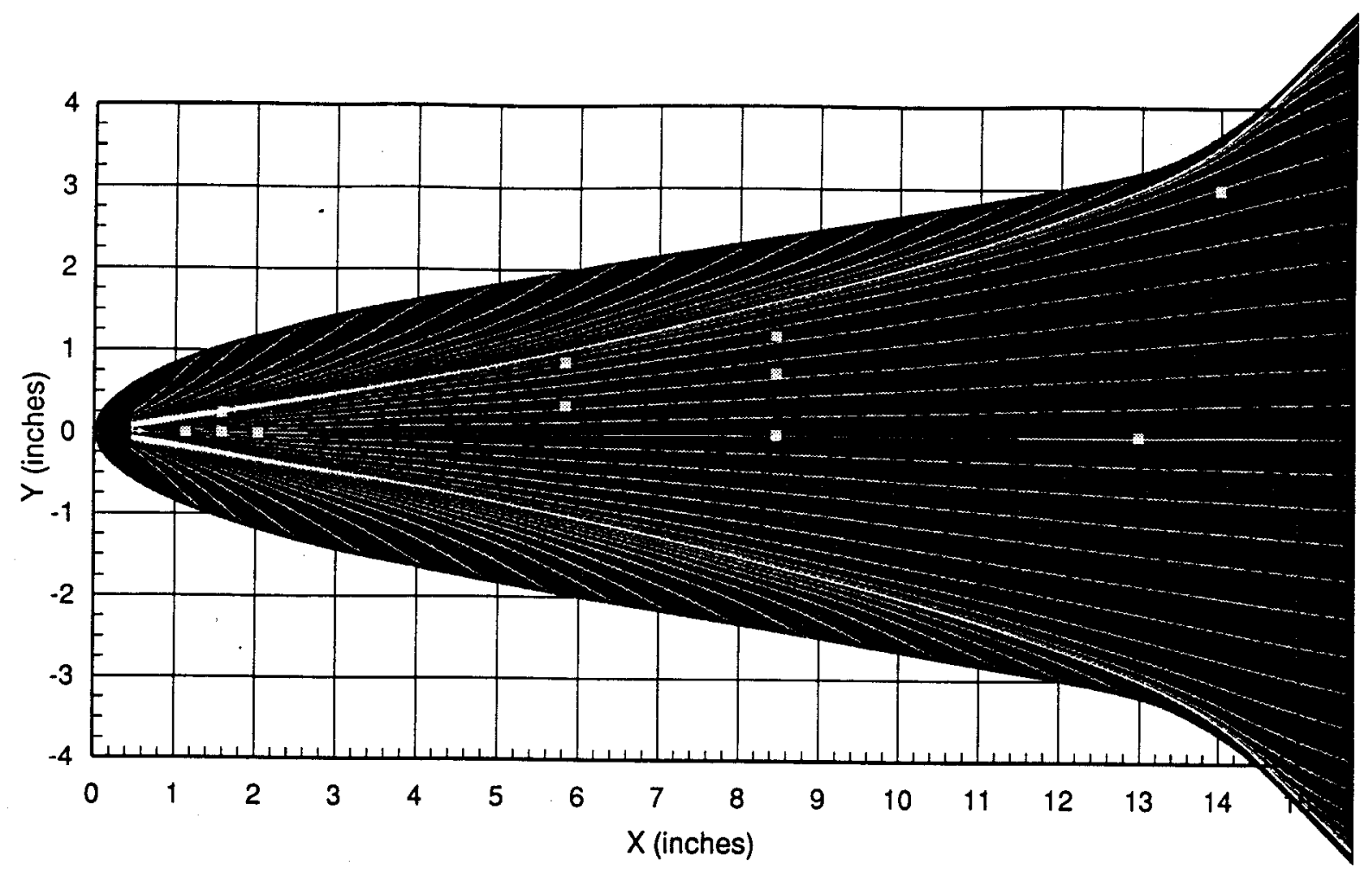

Figure 9 - Inviscid (IVEC3D) Streamline Traces and Roughness Element Locations on AEDC Orbiter Model Windward Surface - Mach $=8, \operatorname{Re} / \mathrm{ft}=1 \times 10^{6} ;$ Alpha $=40^{\circ}$.

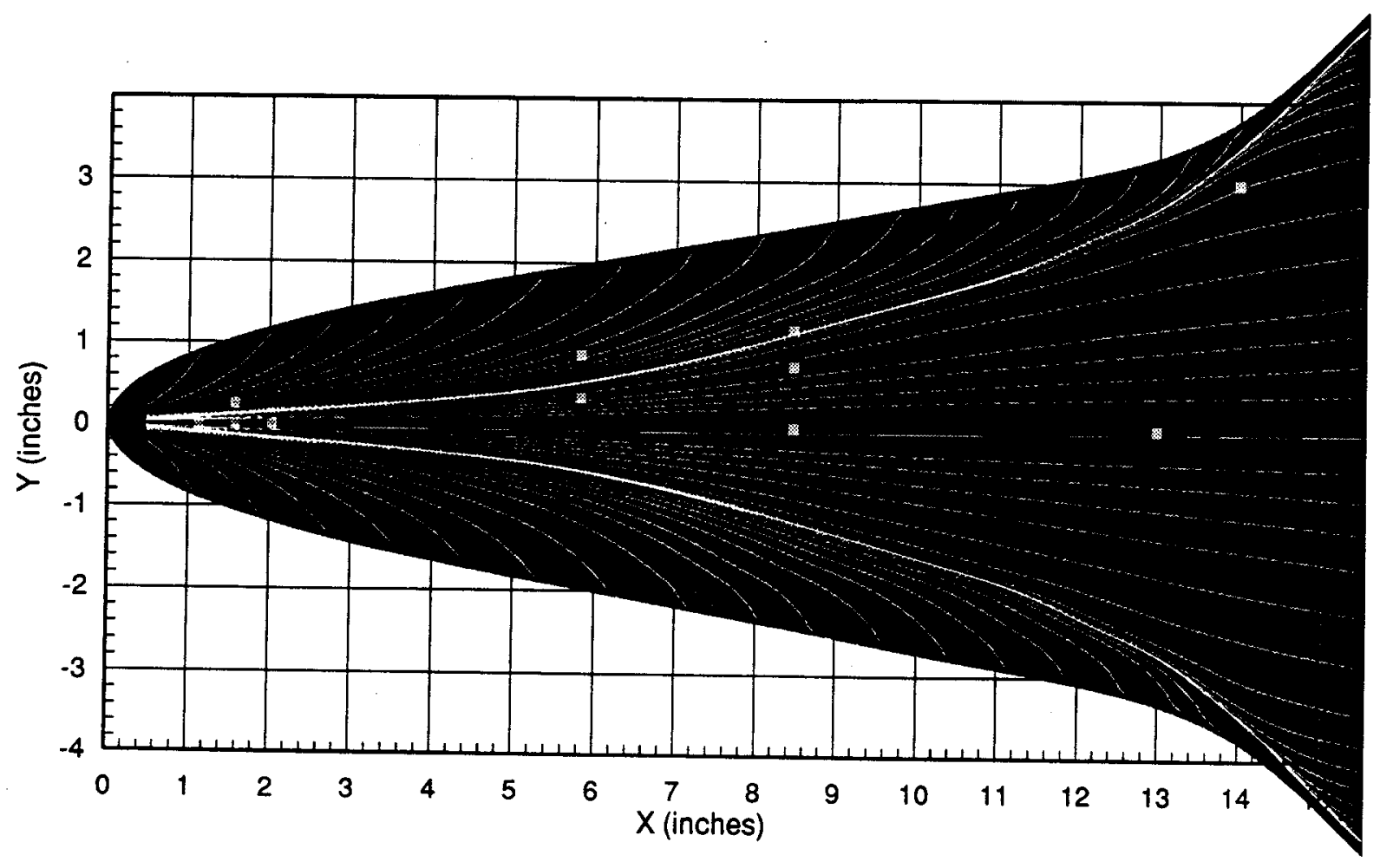

Figure 10 - Viscous (LAURA) Streamline Traces and Roughness Element Locations on AEDC Orbiter Model Windward Surface - Mach $=8, \operatorname{Re} / \mathrm{ft}=1 \times 10^{6} ;$ Alpha $=40^{\circ} ; T_{W}=193^{\circ} \mathrm{R}$. 


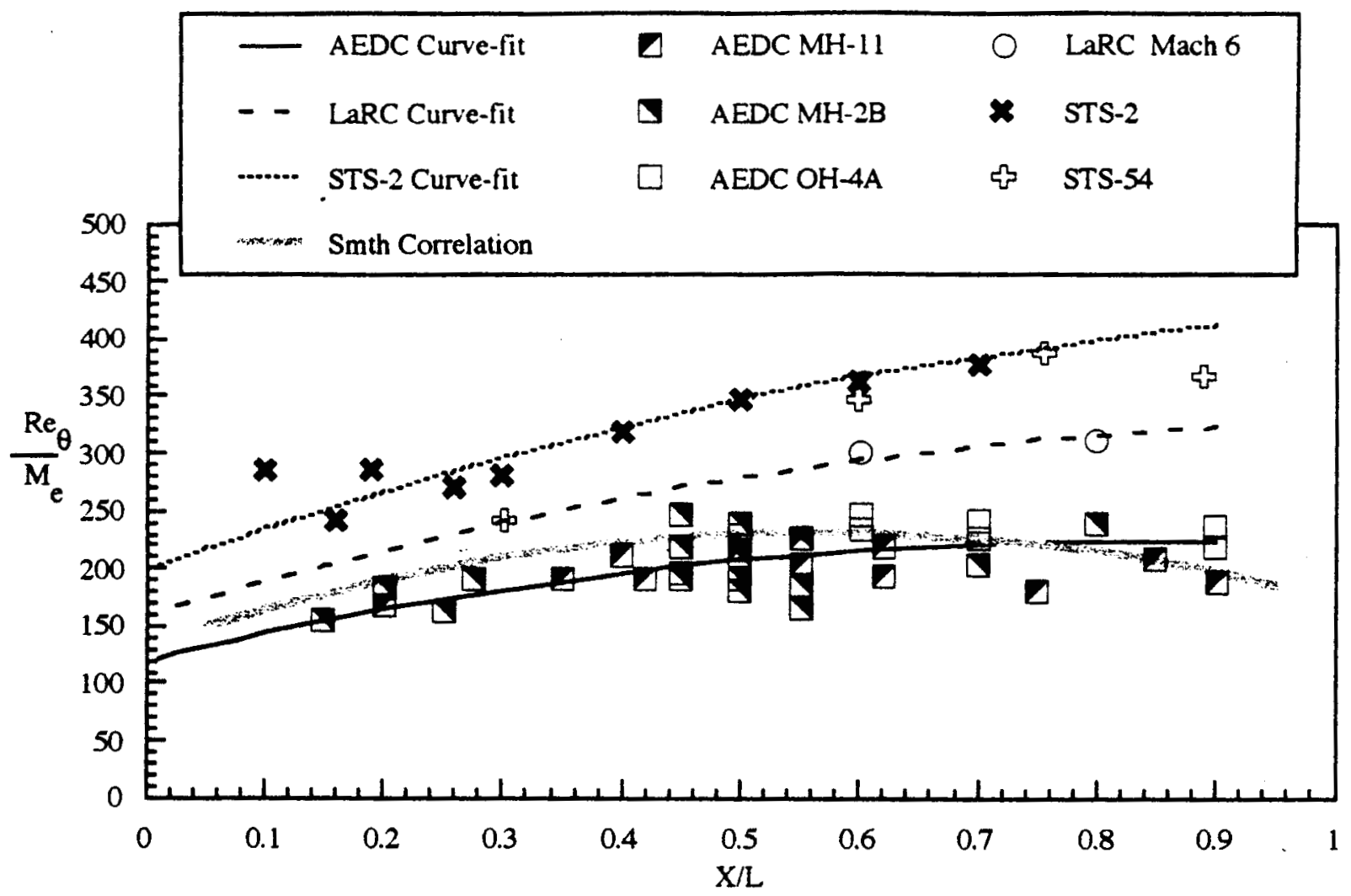

(a) Momentum Thickness Reynolds Number divided by Edge Mach Number

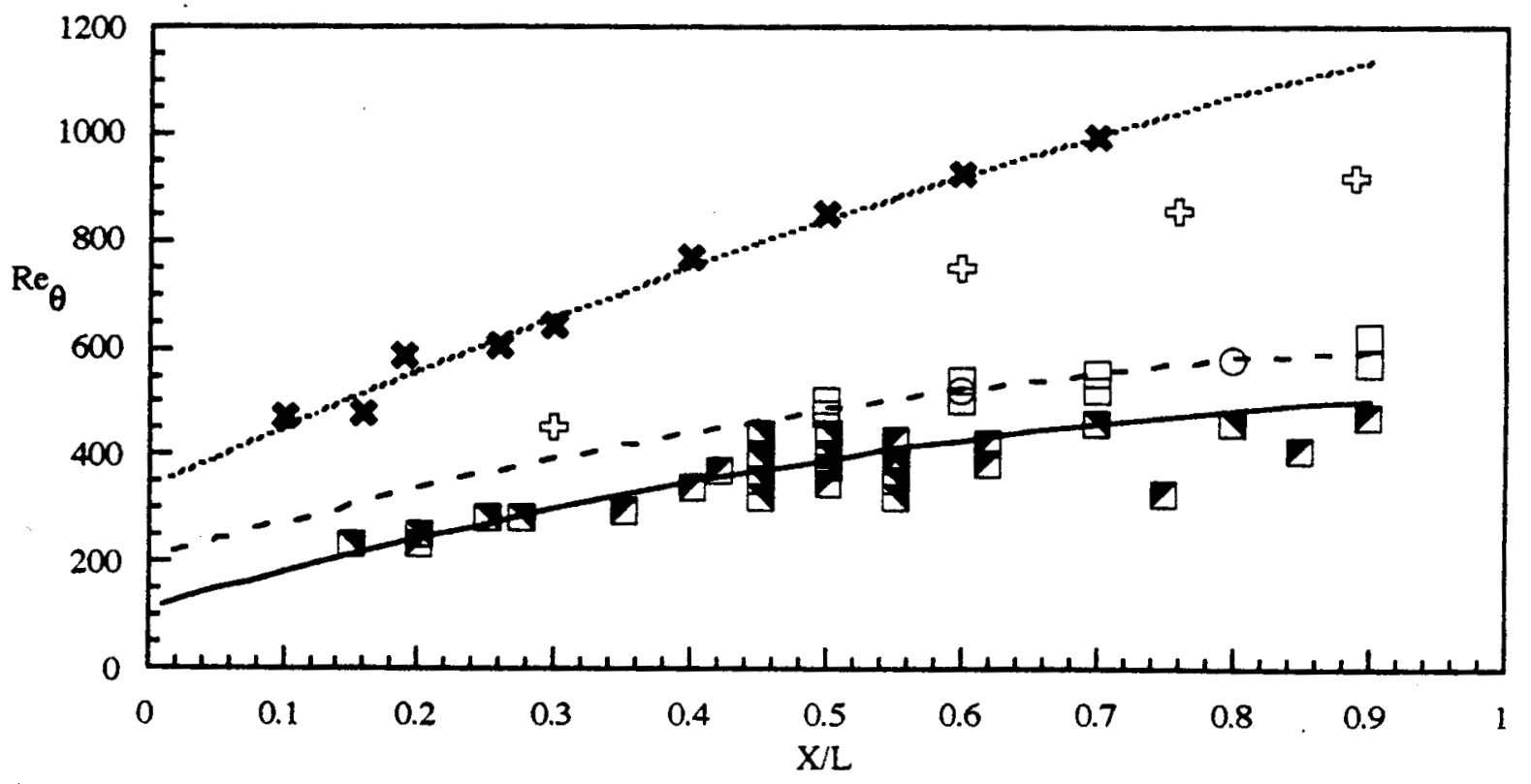

(b) Momentum Thickness Reynolds Number.

Figure 12 - Comparison of Smooth and Distributed Roughness Transition Results. 


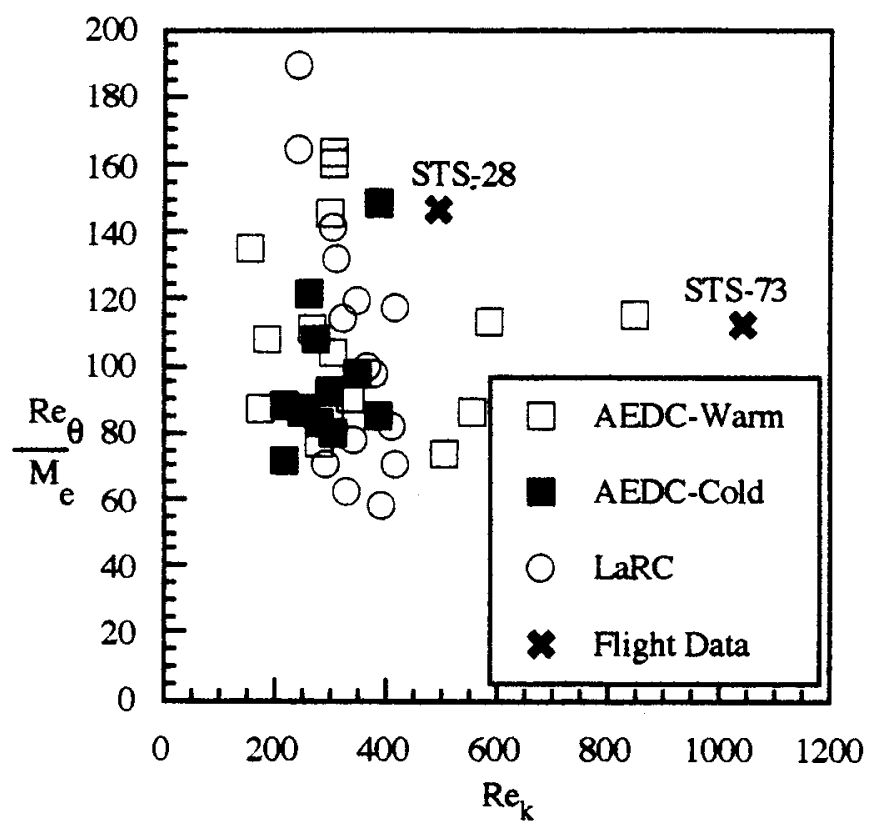

Figure 13 - Roughness Reynolds Number Correlation.

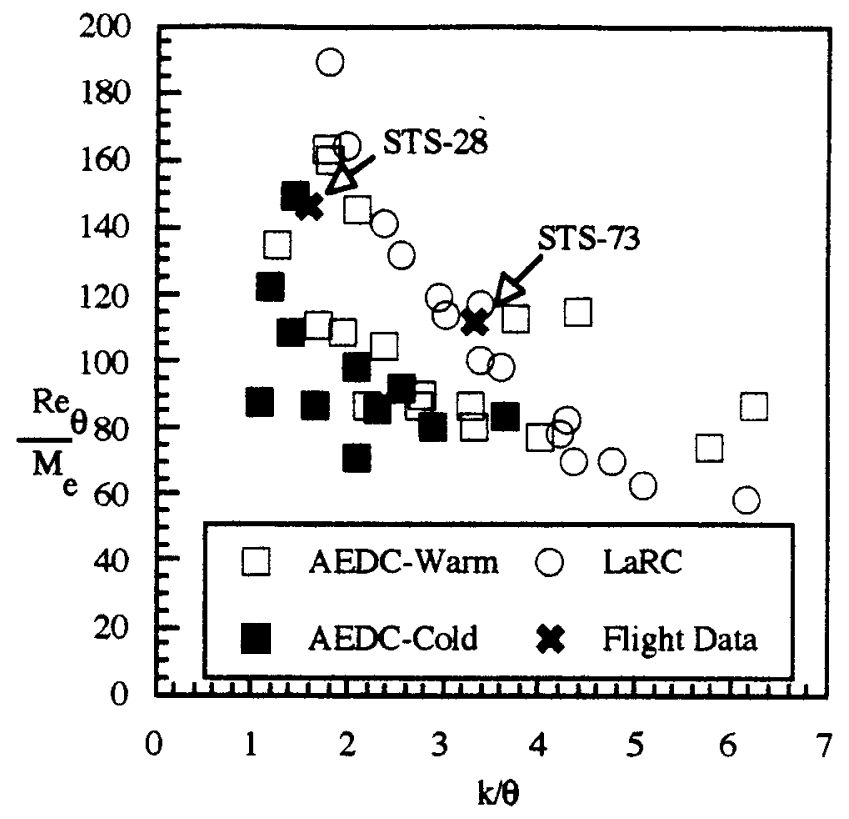

Figure 15 - Correlation using Roughness Height nondimensionalized by Boundary-Layer Momentum Thickness.

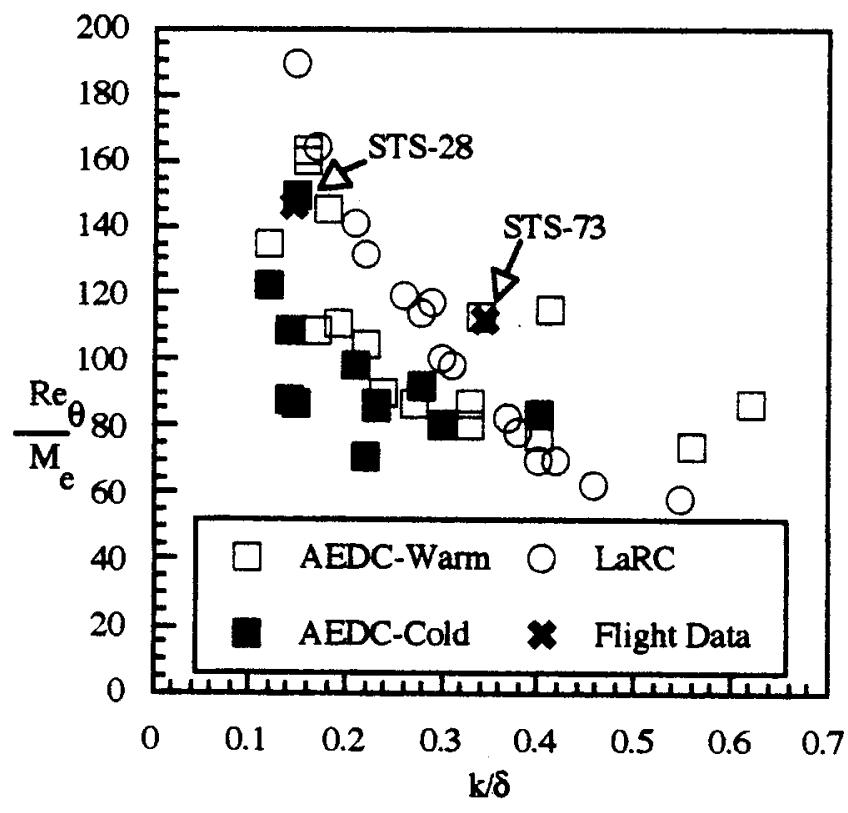

Figure 14 - Correlation using Roughness Height nondimensionalized by Boundary-Layer Thickness.

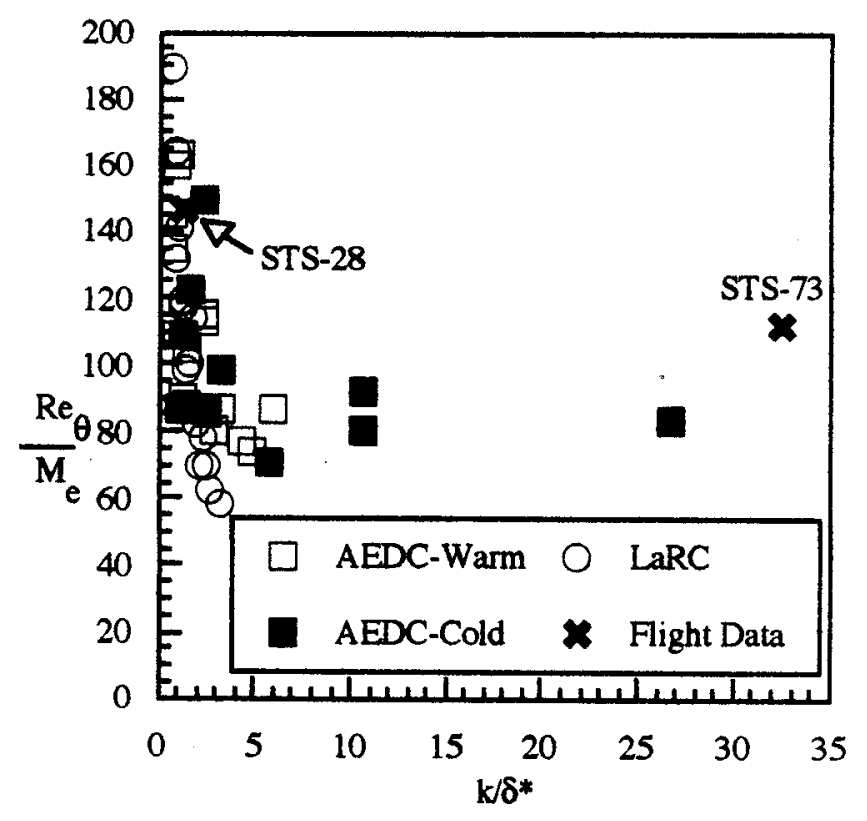

Figure 16 - Correlation using Roughness Height nondimensionalized by Boundary-Layer Displacement Thickness. 


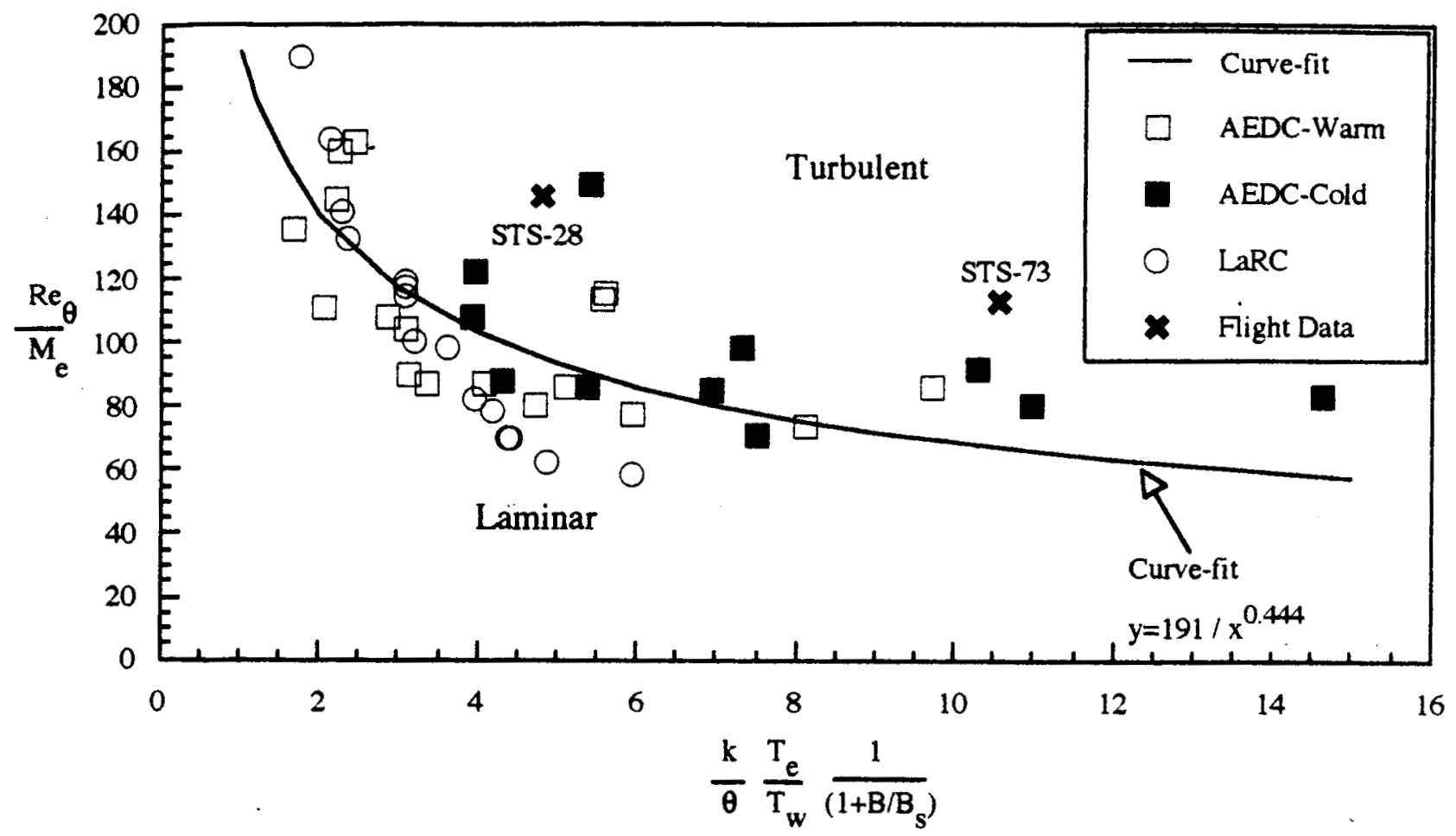

Figure 17 - Modified PANT Roughness Transition Correlation.

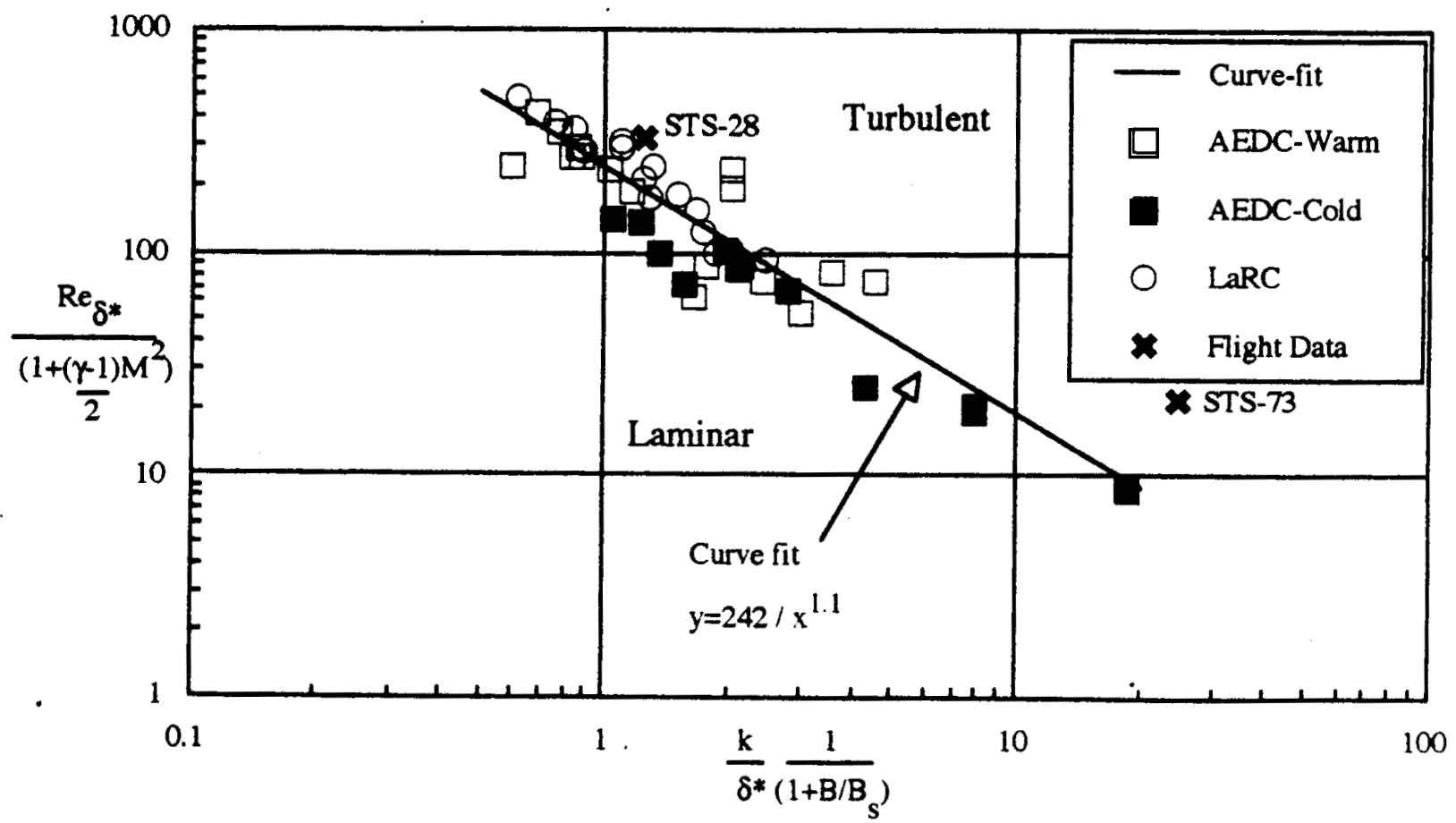

Figure 18 - Modified Van Driest Roughness Transition Correlation. 